

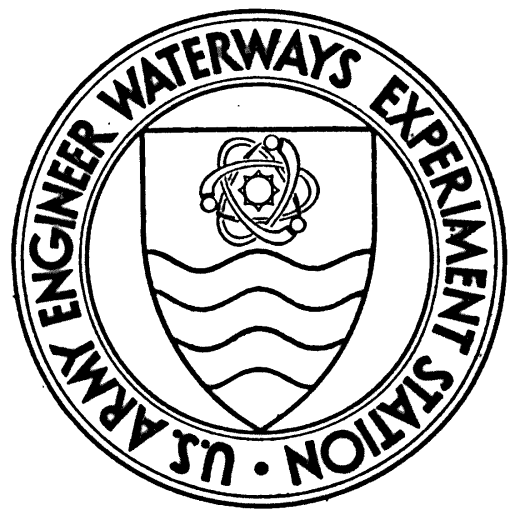

MISCELLANEOUS PAPER S-7I-9

\section{CALCULATION OF STRESS AND STRAIN FROM TRIAXIAL TEST DATA ON UNDRAINED SOIL SPECIMENS \\ by}

J. Q. Ehrgott

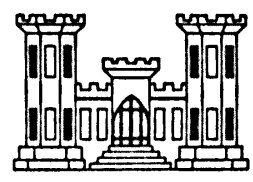

May 1971

Sponsored by Defense Atomic Support Agency

Conducted by U. S. Army Engineer Waterways Experiment Station, Vicksburg, Mississippi 


\section{ABSTRACT}

The formulation of constitutive relations for use in computerized analyses of free-field ground shock phenomena is based primarily on laboratory-determined material properties. These properties, as described by stress-strain relations, are not directly determined in the laboratory, but are derived through interpretation of load and deformation data measured by the experimenter. Throughout this paper, one laboratory test, the triaxial shear test, is used to illustrate the extent of interpretation required on raw data and the influence of this interpretation on recommended constitutive properties. Various techniques that have been developed to obtain stress-strain data from the triaxial test are reviewed along with current advances in measurement systems.

Typical raw data are presented and calculations of axial, lateral, and volumetric strains are made based on a variety of empirical and theoretical approaches. The results demonstrate that research and development efforts are still required in the area of material property testing in order to establish adequate confidence in the formulation of constitutive relations for ground shock calculations. 
This paper was prepared for presentation at the Eric H. Wang Symposium on Protective Structure Technology held at the Air Force Weapons Laboratory, Kirtland Air Force Base, New Mexico, 2l-23 July 1970. The subject matter presented herein was primarily intended for those persons involved in the field of ground motion prediction, but not necessarily familiar with the area of material property determination.

The laboratory equipment and techniques described in this report were developed in support of research on propagation of ground shock through soil and rock being conducted by personnel of the Soils Division, U. S. Army Engineer Waterways Experiment Station (WES), for the Defense Atomic Support Agency (DASA).

This report was prepared and presented by Mr. J. Q. Ehrgott, Impulse Loads Section, Soil Dynamics Branch, Soils Division, WES. Helpful comments and guidance were provided by Mr. J. G. Jackson, $\mathrm{Jr}$., Chief, Impulse Loads Section. Mr. R. W. Cunny was Chief of the Soil Dynamics Branch and Mr. James P. Sale was Chief of the Soils Division. Directors of the WES were COL Levi A. Brown, CE, and COL Ernest D. Peixotto, CE. Technical Director was Mr. F. R. Brown. 


\section{CONTENTS}

ABSTRACT-

PREFACE-

NOTATION-_- 8

CONVERSION FACTORS, BRITISH TO METRIC UNITS OF MEASUREMENT--.--_- 10

CHAPTER 1 INTRODUCTION- 11

CHAPTER 2 THE TRIAXIAL TEST

2.1 Test Description- 13

2.2 Measurement System-16

2.3 Measurement Errors-

2.4 Typical Results-_.

CHAPTER 3 INTERPRETATION OF RAW DATA-_. 26

3.1 Determination of Volumetric Strain-_. 26

3.1.1 Method V-1-_.

3.1.2 Method V-2-1

3.1.3 Method V-3- 30

3.1.4 Method V-4_. 31

3.1.5 Method V-5

3.1.6 Method V-6-1 32

3.1.7 Summary-n 32

3.2 Determination of Deviator Stress and Strain-_....... 33

3.2.1 Method S-1- 35

3.2.2 Method S-2

3.2.3 Method S-3-... 36

3.2 .4 Method S-4

3.2.5 Method S-5- 38

3.2 .6 Method S-6

3.2.7 Summary- 39

CHAPTER 4 DISCUSSION OF INIERPRETATION METHODS-

4.1 Comparison for Hydrostatic Tests- 58

4.2 Comparison for Shear Tests-a 62

CHAPTER 5 CONCLUSION- 73

REFERENCES- 75

FIGURES

2.I Data available from the triaxial test- 22

2.2 Schematic of WES high-pressure triaxial test device-...... 23 
2.3 Typical constant p-type triaxial test results for a sandy clay-......... 24

2.4 Typical constant $\sigma_{r}$-type triaxial test results for a siltstone-.......

3.1 Deformed shapes of specimens during hydrostatic loading--.- 41

3.2 Triaxial specimen of recompacted clayey silt after being subjected to 500-psi hydrostatic pressure, shape IC-...-...- 42

3.3 Triaxial specimen of recompacted clayey silt after being subjected to 5,000-psi hydrostatic pressure, shape IC-.-.-- 43

3.4 Triaxial specimen of a silty clay with rock fragments after being subjected to 1,000-psi hydrostatic pressure, shape IIA-_-_. 44

3.5 Triaxial specimen of silty clay with rock fragments after being subjected to 5,000-psi hydrostatic pressure, shape IIA-_..-1.-1 45

3.6 Cross section of shapes considered in Method V-1.........- 46

3.7 Cross section of assumed shape used in Method V-2-.......- 46

3.8 Cross section of assumed shape used in Method V-3-........ 46

3.9 Assumed shape used in Method V-4_........................ 46

3.10 Summary of methods used to calculate volumetric strain-.-.- 47

3.11 Shapes of failed specimens after shear test-............... 48

3.12 Triaxial specimen of sandstone after shear failure during a dynamic constant p-type test, shape IIA-_...........-.. 49

3.13 Triaxial specimen of recompacted clayey silt after being subjected to a small deviator stress while maintaining a confining pressure of 5,000 psi-_......... 50

3.14 Triaxial specimen of modeling clay prior to test-........- 51

3.15 Triaxial specimen of modeling clay after application of a small deviator stress while a confining pressure of 5,000 psi is maintained-....... 52

3.16 Triaxial specimen of modeling clay after application of a larger deviator stress while a confining pressure of

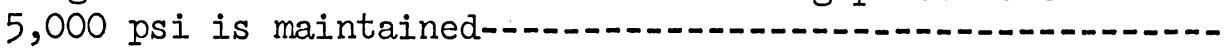

3.17 Triaxial specimen of modeling clay after application of large (postyield) deviator stress while a confining pressure of 5,000 psi is maintained-................... 54

3.18 Specimen deformation during shear test_................- 55

3.19 Cross section of specimen showing assumed deformed shapes considered in Method S-1............... 56

3.20 Cross section of assumed deformed shape considered in Method S-2-_... 56

3.21 Cross section of assumed deformed shape considered in Method S-4-_........... 56

3.22 Distribution of axial strain along length of a specimen---- 56 
3.23 Summary of methods used to calculate deviator stress and

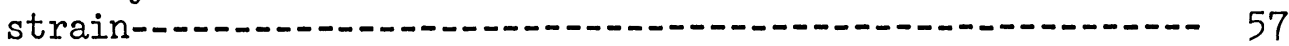

4.I Comparison of methods used to calculate volumetric strain

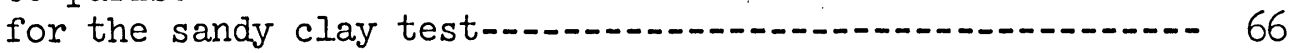

4.2 Comparison of methods used to calculate volumetric strain

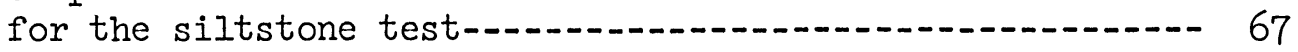

4.3 Comparison of methods used to calculate deviator stress and deviator strain for the sandy clay test.............-. 68

4.4 Initial portion of plots shown in Figure 4.3-......... 69

4.5 Comparison of methods used to calculate deviator stress. and deviator strain for the siltstone test--...-.-.-- 70

4.6 Initial portion of plots shown in.Figure 4.5-........- 71

4.7 Comparison of methods used to calculate volumetric strain during shear for the siltstone test-_.................. 72 


\section{NOTATION}

A Area; also, calibration error

A Original area; also, fixed area of ends of test specimen

$\mathrm{A}_{1} \quad$ Current area at midheight of test specimen

B Output error

C Overall accuracy of measurement device

D Diameter of test specimen

$\mathrm{D}_{\mathrm{O}}$ Original diameter of test specimen

$D_{1} \quad$ Current diameter of test specimen at midheight during hydrostatic test

$\mathrm{D}_{2} \quad$ Current diameter of test specimen at midheight during shear test

E Young's modulus

G Shear modulus

$\mathrm{H} \quad$ Height of test specimen

$\mathrm{H}_{\mathrm{O}} \quad$ Original height of test specimen

$\mathrm{H}_{1} \quad$ Current height of test specimen during hydrostatic test

$\mathrm{H}_{2} \quad$ Current height of test specimen during shear test

$\mathrm{K} \quad$ Bulk modulus

p Mean normal stress

R Operator error

$\mathrm{V} \quad$ Volume of test specimen

$\mathrm{V}_{\mathrm{c}} \quad$ Current volume of test specimen during hydrostatic test 


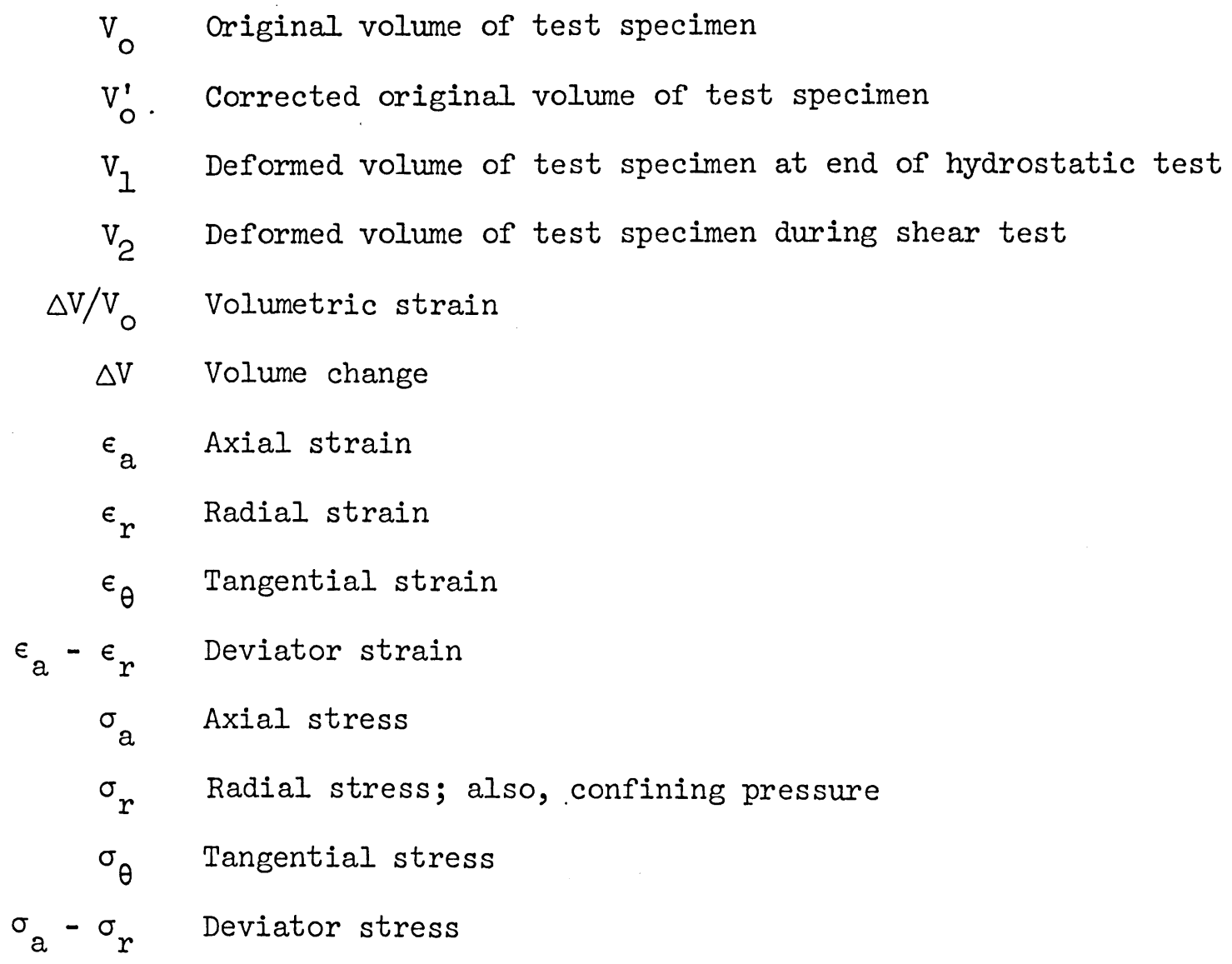


CONVERSION FACTORS, BRITISH TO METRIC UNITS OF MEASUREMENT

British units of measurement used in this report can be converted to metric units as follows.

\begin{tabular}{lll}
\hline \multicolumn{1}{c}{ Multiply } & By & \multicolumn{1}{c}{ To Obtain } \\
\hline mils & 0.0254 & millimeters \\
inches & 2.54 & centimeters \\
feet & 0.3048 & meters \\
pounds per square inch & 0.070307 & $\begin{array}{l}\text { kilograms per square } \\
\text { centimeter }\end{array}$ \\
pounds per cubic foot & 16.01846 & kilograms per cubic meter
\end{tabular}


CHAPTER 1

INTRODUCTION

The response of any land-based structure to loadings produced by the explosive impact resulting from either conventional high explosive (HE) or nuclear detonations is highly dependent upon the dynamic stress-strain and strength characteristics of the surrounding and supporting earth material. Current wave-propagation computer codes used in the prediction of free-field stresses and motions require stress-strain constitutive relations for the earth materials at the sites of interest. Generally, such relations are derived from laboratory tests on undrained soil and/or rock specimens conducted under a variety of states of impulsive-type stress and at magnitudes closely simulating expected field levels. In cases where current equipment limitations only allow the application of static loadings, extrapolation of test results must be made to reflect dynamic conditions.

The derivation of stress-strain properties from laboratory data, however, is subject to analysis and interpretation by the experimenter. It is the intent of this paper to illustrate, by examples, the influence that analyses and interpretations have on stress-strain relations obtained from raw test data. It is realized that a continuing effort is being made to solve and/or improve the uncertainties affecting laboratory tests; however, the techniques presented herein are representative of the approaches currently being used to obtain stress-strain relations during production-type testing programs.

In order to best illustrate how the raw data are analyzed, one laboratory test, the triaxial shear test, will be used throughout this paper; similar illustrations can be obtained from any other laboratory test based on its peculiar limitations and problems. Since many of those involved with the development of constitutive relations 
may be unfamiliar with some areas of laboratory techniques, Chapter 2 of this paper will present a general review of the triaxial test and recent advances made in measurement systems. In Chapter 3, various methods used to calculate volumetric strain, deviator stress, and deviator strain from raw data will be derived, and in Chapter 4, stress-strain relations derived using the various calculation methods and raw data obtained from two triaxial tests will be compared and discussed. 
CHAPTER 2

THE TRIAXIAL TEST

\subsection{TEST DESCRIPTION}

The triaxial test, when properly instrumented so as to provide complete load and deformation data, is one method for determining soil and rock stress-strain behavior and shear strength. Because triaxial test equipment is designed to permit separate control of both lateral and axial loadings, the test can provide data on the fundamental response characteristics of soil and rock under a wide variety of controlled states of stress. In addition to stress control, the test also permits control of loading rate, drainage conditions, and specimen size. A brief history of the development of the triaxial test is contained in ASTM Special Technical Publication Number 361 (Reference 1), and a detailed description of the apparatus and test procedure is contained in Reference 2 .

Separate pressure control systems are necessary for application of the several possible axial and lateral stress paths. Application of the axial load can be accomplished by any number of methods depending. on whether the test is desired to be stress-controlled or strain-controlled. When the specimen is to be loaded to failure, a strain-control method should be employed; when the behavior of the specimen is to be studied at less-than-failure stress levels, a stress-control method is preferable because of the regulation required in loading increment. Dead loading the sample, either directly or by lever systems, is probably the oldest and simplest stress-control method. Pneumatic systems that apply air pressure to a movable piston can be used to develop not only very large loads (by varying the piston area ratio) but also to develop rapid loading rates. Hydraulic systems employ the same principle but are best suited for straincontrol testing. The use of motor-driven gears is also a very 
effective method of applying a strain-controlled load. Vibratory loads can be achieved by means of a rotating cam system, a pneumatic system employing a sequence valve, springs with a deadweight loading device, and electrically controlled devices. Shock loadings can be accomplished by dropping weights, pneumatic loading systems, or explosive charges.

Confining pressures can be achieved by means of any number of systems employing air compressors, hydraulic pumps, bottled gas, or piston-type multipliers. At lower pressure levels (less than 500 $\mathrm{psi}^{\mathrm{I}}$ ), the use of gas as a chamber fluid provides easy control of the confining pressure. At higher pressures, a hydraulic fluid must be used for reasons of safety; however, a hydraulic fluid becomes difficult to control as the specimen changes in volume and a more complex supply system is required.

In the standard triaxial configuration, the specimen is placed in a cylindrical chamber. The axial load is applied to the specimen by a piston, which enters through a sealing device (piston guide) in the top of the triaxial cell. The inside of the chamber can be pressurized to provide a lateral loading or confining pressure on the specimen. Generally, the cylindrical specimen is sealed from the chamber fluid by a thin membrane, and the specimen is sandwiched between two rigid plates that provide the transfer of load between the piston and the specimen.

The triaxial specimen has a cylindrical shape with a height-todiameter ratio of approximately $2: 1$. Axial load is applied in the vertical direction or along the $z$ axis. Lateral loading is applied radially around the specimen or along the $r$ axis. In the general analysis of the triaxial specimen, it is assumed that the tangential stress and strain are equal in magnitude to the radial stress and 1

A table of factors for converting British units of measurement to metric units is presented on page 10. 
strain (i.e., $\sigma_{\theta}=\sigma_{r}, \epsilon_{\theta}=\epsilon_{r}$ ) and that the stress and strain distribution throughout the specimen is uniform. Although investigations such as those in References 3 and 4 have shown that stress and strain distribution within triaxial specimens is generally not uniform, the uniformity assumptions are currently necessary to the overall analysis of the test results.

Since the specimen is completely within the chamber during loading, the confining pressure $\sigma_{r}$ not only acts radially on the specimen, but also vertically. Hence, the axial loading on the specimen is the sum of the axial force of the piston $p$ and the axial force exerted by the confining pressure. The total axial force divided by the specimen area (perpendicular to direction of loading) is defined as the axial stress $\sigma_{a}$. Soil mechanists define the difference between the axial stress and the confining pressure as the deviator stress $\left(\sigma_{a}-\sigma_{r}\right)$.

Assuming for the moment that the test specimen is elastic, homogeneous, and isotropic and deforms as a cylinder. Figure 2.1 illustrates some of the states of stress that can be imposed on the specimen along with typical stress-strain responses. For a hydrostatic state of stress where $\sigma_{a}=\sigma_{r}$, the mean normal stress $p=\frac{\sigma_{a}+2 \sigma_{r}}{3}$ increases and the deviator stress $\left(\sigma_{a}-\sigma_{r}\right)$ remains zero. The specimen response is usually plotted as a pressure-volumetric strain curve, whose slope is the bulk modulus $k$. In a shear test, the specimen is first loaded hydrostatically to some level of $p$. In cases where the confining pressure is held constant while the deviator stress is increased, the specimen response is usually plotted as a deviator stress versus axial strain $\epsilon_{a}$ curve, the slope of which is Young's modulus $E$. In cases where the confining pressure is decreased while the axial stress is increased so that the mean normal 
stress is held constant, the response is usually plotted as a deviator stress versus deviator strain $\left(\epsilon_{a}-\epsilon_{r}\right)$ curve, the slope of which is two times the shear modulus G. In addition to the modulus data, yield strength can also be obtained. Several shear tests conducted at different levels of $p$ provide data to describe a yield envelope.

of course, many other variations can be conducted, such as the extension test in which the confining pressure is held constant and the axial stress is decreased. Yield strength values obtained from such tests describe a lower bound yield envelope.

\subsection{MEASUREMENT SYSTEM}

At the heart of any test device is the measurement system that reports the specimen's response. In the triaxial test, as in most tests designed to obtain earth material properties, there is no one universal measurement system because of the broad range of loads and deformations encountered. The system that will be presented is unique to the U. S. Army Engineer Waterways Experiment Station (WES) and used mainly for soils and soft rocks; several individual units are used for various measurement ranges.

The static confining pressure felt by the specimen can be measured by a number of commercially produced items such as pressure transducers and gages. In a dynamic test, special pressure transducers are mounted within the confining chamber.

The axial load is best measured directly on the soil specimen to eliminate the influence of piston friction, especially during highpressure cyclic tests. The intemal load cell must be precalibrated for pressure effects, however. In a dynamic test, two load cells are used (one above and one beneath the specimen) to provide a cross reference as well as to monitor wave propagation in those tests in which 
the specimen might be loaded too fast.

Although the measurement of load and pressure is fairly straightforward, measurement of specimen deformation is not so simple. All measurements on undrained specimens must be made external to the specimen, and the devices used for such measurements must not restrict or otherwise influence the natural deformation of the specimen. Further, they must be relatively free from pressure influences and, in the case of dynamic tests, able to respond to the speeds involved. The simplest method for measuring axial deformation is to measure the movement of the axial load piston outside the chamber. However, during the hydrostatic phase of a triaxial test, a problem develops, especially in a dynamic test, as to how to ensure piston contact with the specimen. An axial deformation method recently incorporated into the WES dynamic triaxial test device employs two vertical deformeters, consisting of commercially produced LVDT's mounted at 180 degrees to each other, to monitor the movement of the top cap. The devices allow for free deformation of the specimen, require only a nominal amount of force to be moved, and permit in-place calibration and pressure checks. An external piston measurement system is also employed during the shear phase as a cross-check of systems, since the application of deviator stress during this phase ensures contact between the piston and the specimen.

The lateral deformations of the specimen are very difficult to evaluate properly. Not only does the specimen deform laterally, but also downward, so that points on its surface do not move in a perfectly radial plane. Further, the specimen does not necessarily deform uniformly so that a single lateral measurement may not be completely representative. Coupled with these problems is the fact that there is a rubber membrane surrounding the specimen and its contribution to the measured movement also has to be evaluated. Hence, in 
order to make any measurement of strain in the radial direction, some problems have to be neglected during the actual test measurements and then accounted for during evaluation of results.

of the many devices which have been developed for measurement of lateral strain, the one described in Reference 5 appears to be the best suited for static tests. The device measures changes in diameter of the specimens by means of cantilever springs, which are instrumented with electrical resistance strain gages. The lateral deformeter is simple in design, easy to install, and exerts little if any force on the specimen. Several of these devices can be arranged at different elevation levels around the specimen so that a fairly complete deformation profile can be obtained. Also, and most important, the device allows for in-place calibration, including that for pressure effects. Another system, utilizing commercially produced LVDT's, is best employed for tests in which the confining pressure is dynamically applied. This device has physical limitations, such as range, and it is easily damaged during uncontrolled specimen rupture.

Figure 2.2 shows a cutaway schematic of the WES high-pressure triaxial test chamber with the measurement system in place around the specimen. The electrical outputs from the various systems go through amplifiers and are recorded on a direct-writing, light-beam oscillograph.

\subsection{MEASUREMENT ERRORS}

For a given measurement device, there are generally three sources of error, i.e. calibration error, output error, and operator error. Calibration error $( \pm A)$ is related to the accuracy of the device used as a standard and the associated errors that occur during the calibration; +2 percent is reasonable in a production-type program. Output error $( \pm B)$ is a function of the measuring device and system including 
such items as electronics, temperature effects, etc. A value of \pm 1 percent is reasonable; however, that error increases to about \pm 2 percent when operating at less than 10 percent of full range. Operator error $( \pm R)$ is a function of the recorded output and is a given percentage of the range of current interest. For an oscillograph record, the error is based on the maximum working range of the oscillograph and the operator's readability; a value of \pm 0.5 percent is considered reasonable. The overall accuracy ( $(+\mathrm{C})$ of the measurement device can then be expressed by the following equation

$C= \pm\left[( \pm B \times \text { full electrical output value })^{2}\right.$

$+( \pm R \times \text { full electrical output value })^{2}$

Where:

$$
\left.+( \pm \mathrm{A} \times \text { measurement of interest })^{2}\right]^{1 / 2}
$$

$$
\begin{aligned}
& B= \pm 1 \text { to } 2 \text { percent } \\
& R= \pm 0.5 \text { percent } \\
& A= \pm 2 \text { percent }
\end{aligned}
$$

For example, assume that a test is to be conducted during which the maximum deformation of the material is estimated to be $500 \mathrm{mils}$ and that the most suitable measurement instrument with a range exceeding the expected maximum deformation has a full linear range of 1,000 mils. Also assume that the recorded output of the unit can be increased by adjusting the amplifier gain so that the full electrical output is generated by a 500-mil mechanical input. The accuracy of a measured 500-mil deflection would be

$$
\begin{aligned}
C & =\left[(0.01 \times 500)^{2}+(0.005 \times 500)^{2}+(0.02 \times 500)^{2}\right]^{1 / 2} \\
& \approx \pm 11-1 / 2 \mathrm{mils} \text { or } \pm 2-1 / 3 \text { percent }
\end{aligned}
$$


If, however, the actual maximum deformation of the specimen is only $50 \mathrm{mils}$ or even if the specimen deformed $500 \mathrm{mils}$, but data are required at the initial part of the test, say at the 50-mil deformation point, then the accuracy of the measured 50-mil deformation would be

$$
\begin{aligned}
C & =\left[(0.02 \times 500)^{2}+(0.005 \times 500)^{2}+(0.02 \times 50)^{2}\right]^{1 / 2} \\
& \approx \pm 10-1 / 3 \mathrm{mils} \text { or } \pm 21 \text { percent }
\end{aligned}
$$

It can be noted from the above examples that care must be taken to select measurement instruments that provide the greatest possible accuracy over the range of interest. The selection depends on two factors: experience in estimating material response behavior and a predetermined measurement objective such as to obtain initial stressstrain data or to obtain data at the maximum or yield condition.

\subsection{TYPICAL RESULTS}

The recorded load and deformation time histories are converted, through a set of analytical assumptions, to stress and strain histories and displayed for further property analyses in the form of stress-strain plots. Two typical WES static high-pressure triaxial test data plates are shown in Figures 2.3 and 2.4; Figure 2.3 illustrates results for a constant p-type test conducted on a sandy clay specimen and Figure 2.4 illustrates results from a constant $\sigma_{r}$-type test conducted on a clayey siltstone. The sandy clay specimen (Figure 2.3) was first loaded hydrostatically to l,000 psi and then loaded to failure in shear by increasing the deviator stress while the mean normal stress was maintained constant. The siltstone specimen (Figure 2.4) was hydrostatically loaded to 1,500 psi and then loaded to failure in shear by increasing the deviator stress while 
the confining pressure was held constant. The response of each specimen to the hydrostatic loading is seen as a plot of pressure versus volumetric strain, and the response to the shear loading is seen as a plot of deviator stress versus deviator strain. Pertinent information regarding the composition properties of the specimens is also shown on the figures. 

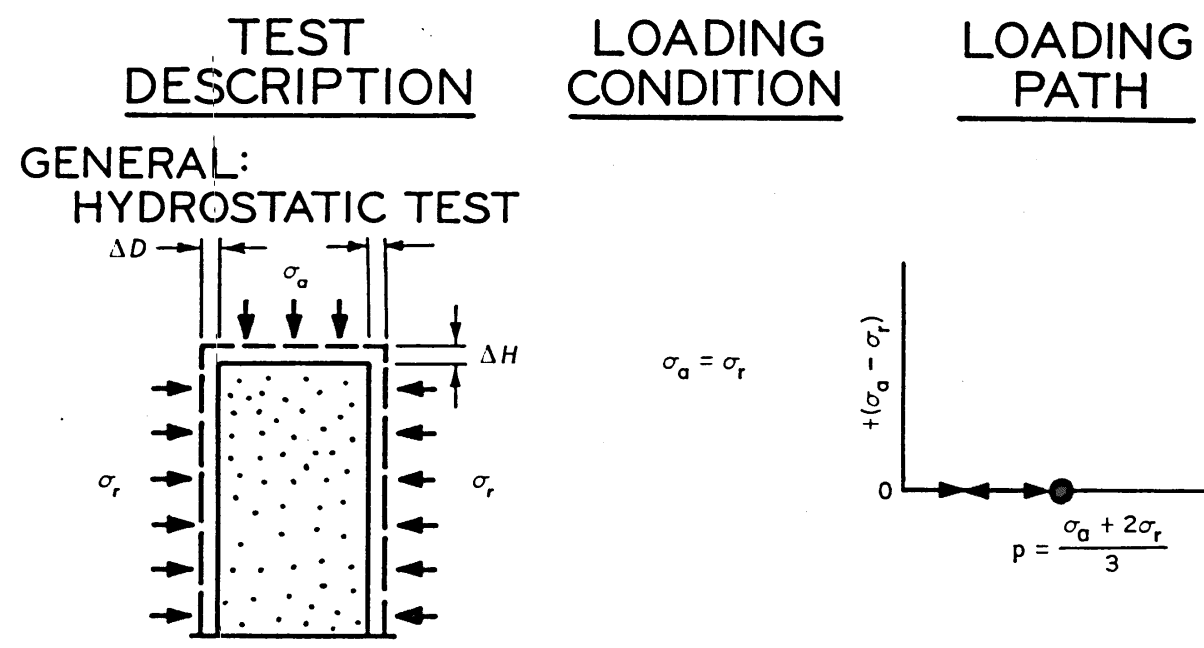

SPECIMEN RESPONSE GENERAL:

HYDROSTATIC TEST
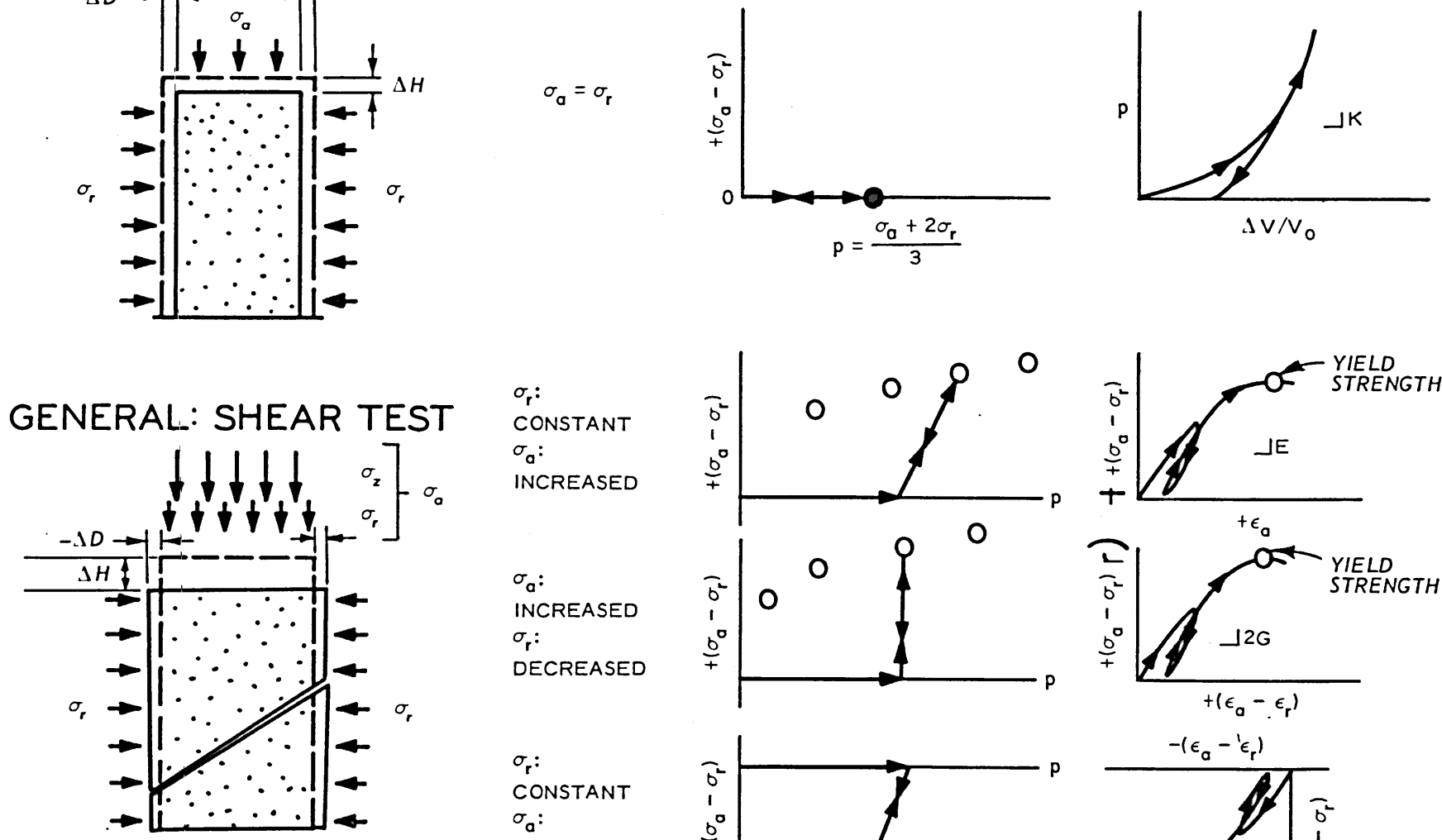

- ORIGINAL SHAPE DEFORMED SHAPE
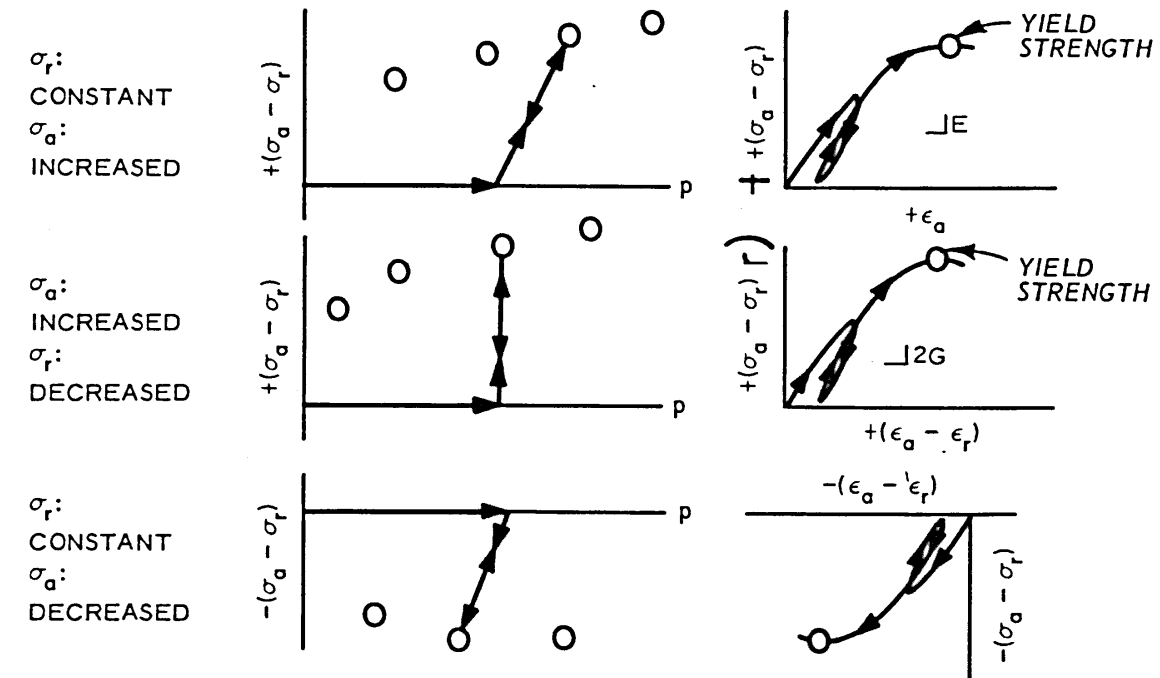

Figure 2.1 Data available from the triaxial test. 


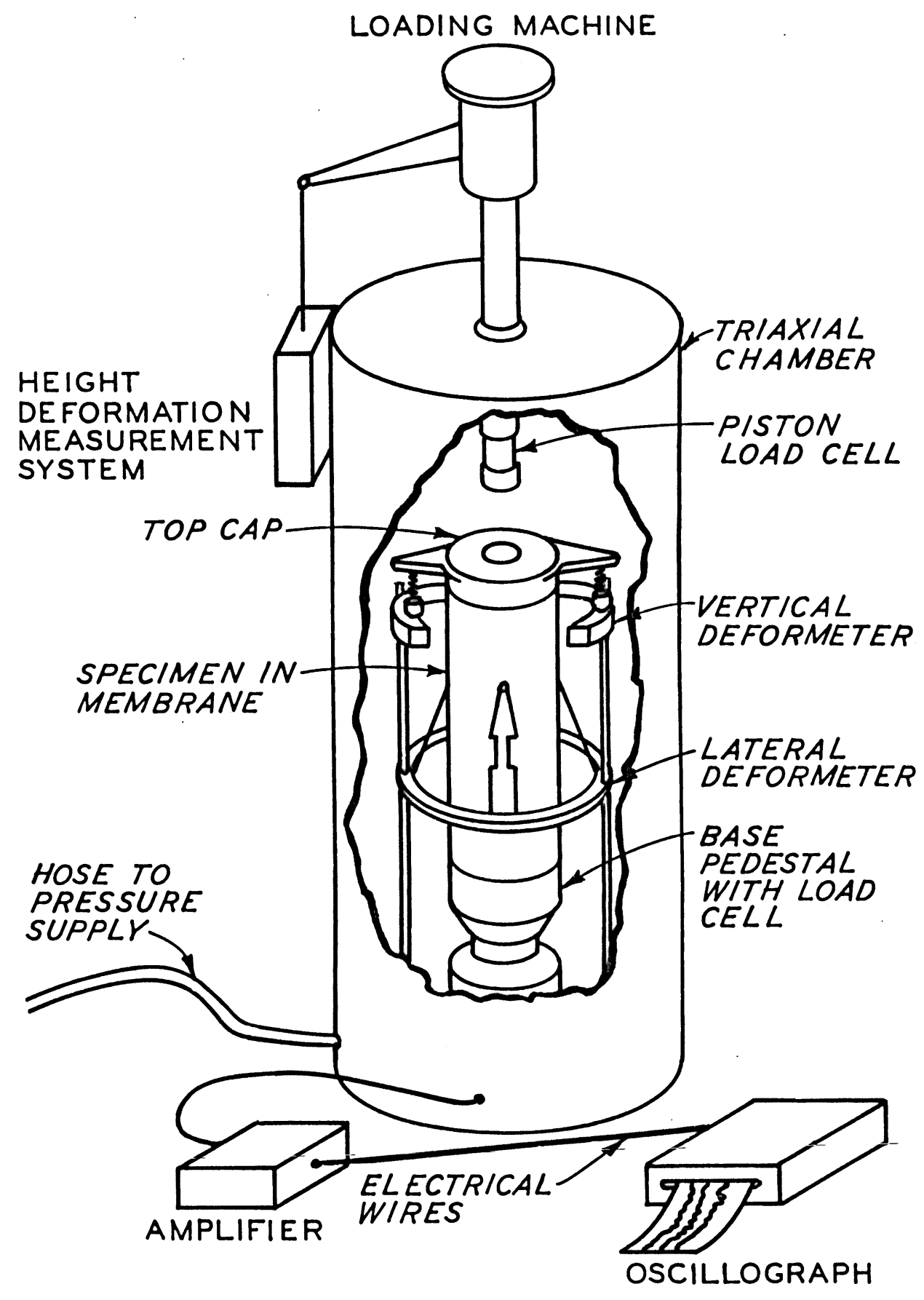

Figure 2.2 Schematic of WES high-pressure triaxial test device. 

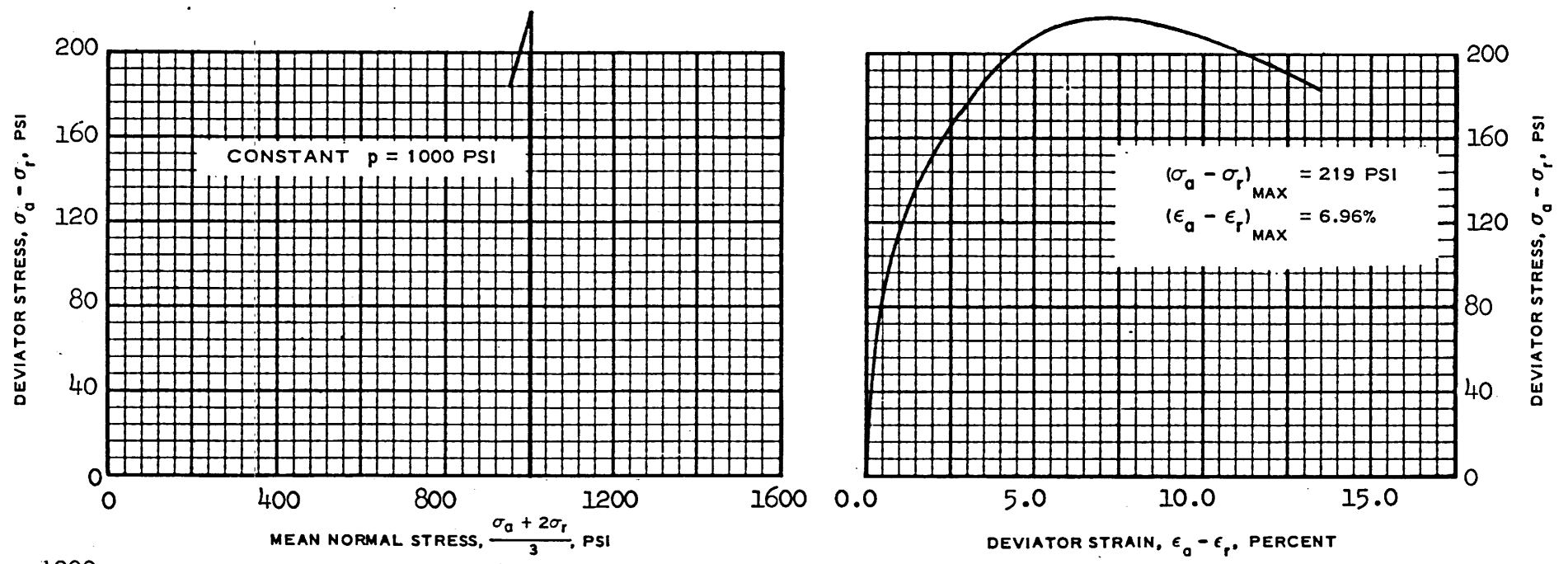

$\stackrel{N}{\mp}$
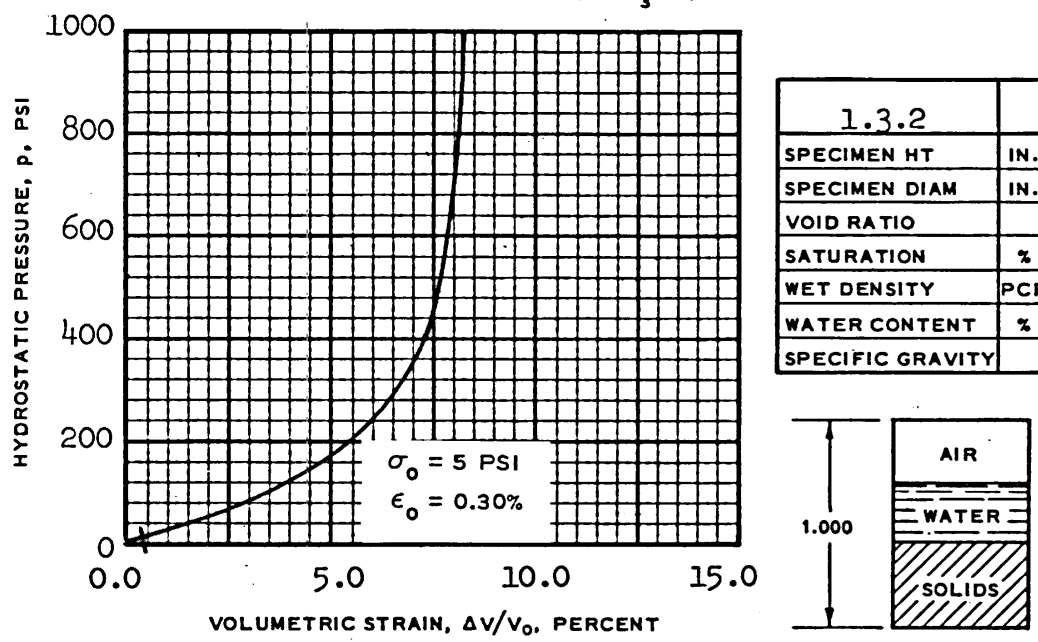

\begin{tabular}{|c|c|c|}
\hline & INITIAL & $\begin{array}{c}\text { END OF HYDRO } \\
\text { COMPR PHASE }\end{array}$ \\
\hline IN. & 2.989 & 2.854 \\
\hline IN. & 1.391 & 1.337 \\
& 0.938 & 0.780 \\
\hline & 73.7 & 88.7 \\
\hline PCF & 108.9 & 118.6 \\
\hline & 25.7 & \\
\hline & 2.69 & \\
\hline
\end{tabular}

$0.127 \quad 0.049$

$0.357 \quad 0.389$

$0.516 \quad 0.562$

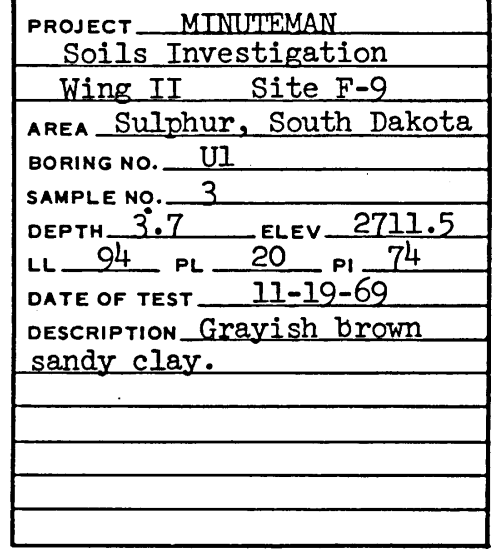

Figure 2.3 Typical constant p-type triaxial test results for a sandy clay. 


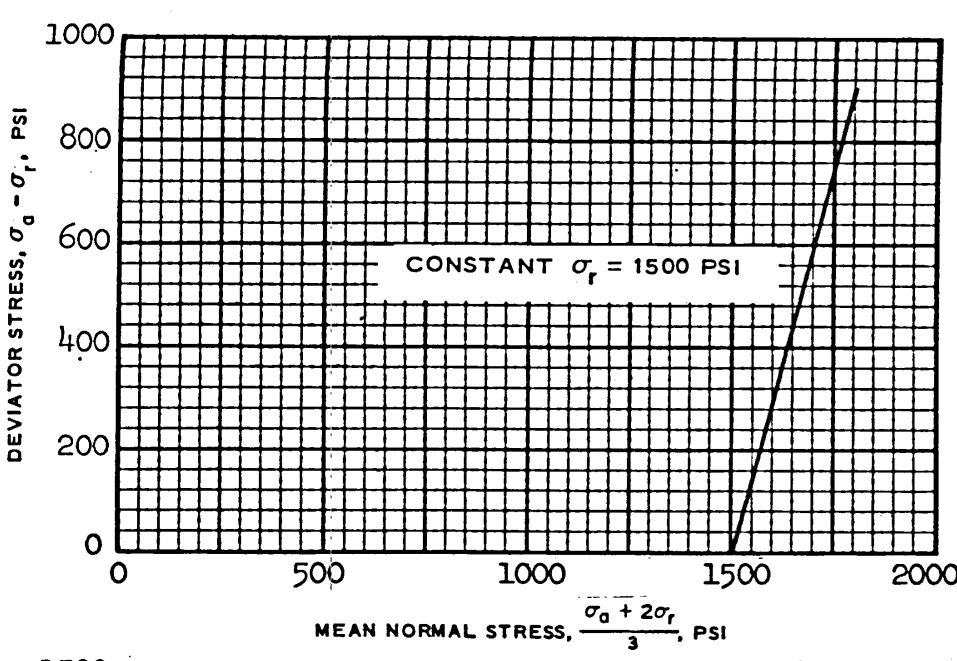

MEAN NORMAL STRESS, $\frac{\sigma_{a}+2 \sigma_{r}}{3}$. PSI

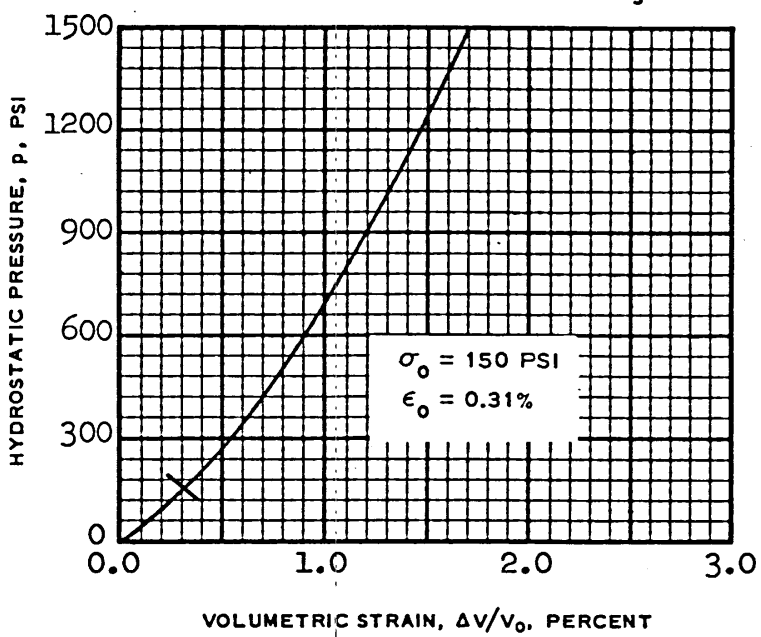

\begin{tabular}{|l|c|c|c|}
\hline 1.74 .8 & & INITIAL & $\begin{array}{c}\text { END OF HYDRO } \\
\text { COMPR PHASE }\end{array}$ \\
\hline SPECIMEN HT & IN. & 2.997 & 2.969 \\
\hline SPECIMEN DIAM & IN. & 1.397 & 1.387 \\
\hline VOID RATIO & & 0.863 & 0.831 \\
\hline SATURATION & $:$ & 93.9 & 97.4 \\
\hline WET DENSITY & PCF & 114.3 & 116.2 \\
\hline WATER CONTENT & $:$ & 31.2 & \\
\hline SPECIFIC GRAVITY & & 2.60 & \\
\hline
\end{tabular}

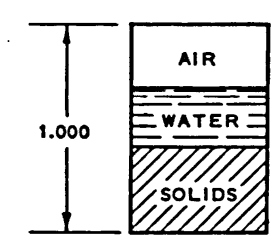

$$
\begin{aligned}
& \frac{0.028}{0.435}-0.012 \\
& 0.442 \\
& 0.537-0.546
\end{aligned}
$$

1000

800

此 600

400

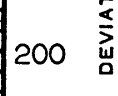

1.0

$\epsilon_{a}-\epsilon_{\mathrm{r}}$ PERCENT

Figure 2.4 Typical constant $\sigma_{\mathrm{r}}$-type triaxial test results for a siltstone. 
CHAPTER 3

INTERPRETATION OF RAW DATA

Between collection of the raw test data and the production of data plots such as those shown in Figures 2.3 and 2.4 , much interpretation and analysis must be done by the material property investigator. This analysis of the raw data has considerable influence on the constitutive properties finally selected to describe the material's behavior. The stress-strain plots shown in the abovementioned figures were based on a certain set of assumptions; other stress-strain plots could have been generated from the same set of raw data using different, yet perhaps equally valid, assumptions. In the following section, some of the various methods and assumptions that can be used to analyze raw data will be described. Then the data from the two previously presented triaxial tests, one on a relatively soft sandy clay (Figure 2.3) and one on a relatively stiff clayey siltstone (Figure 2.4), will be used to illustrate the variations in moduli that can be obtained using the different methods of analysis.

\subsection{DETERMINATION OF VOLUMETRIC STRAIN}

Since deformation measurements are made only at a few specific locations on the specimen surface, it is necessary to assume a complete specimen deformation pattern in order to describe the overall stress-strain response of the specimen to imposed loadings. First, consider some of the general deformed shapes noted during application of hydrostatic loadings. Figure 3.1 shows the two most common shapes, double cone and cylindrical. Specimens deforming as a double cone (IA, IB, IC) undergo maximum lateral deformation at the center while the ends undergo little or no lateral deformation. The deformation restraint at the ends is attributed to end-cap friction (References 
6 and 7). Shear forces at both ends caused by the top cap and base pedestal prevent free movement of the specimen; however, the influence of end caps is not the same on all types of material. Figures II-A, II-B, and II-C of Figure 3.1 show the second type or cylindrical shape. The specimens deform radially in a uniform or nearly uniform manner. The effect of the end caps on the specimen is not as apparent as in the case of the double-cone shape. There is little factual data regarding the distribution of axial deformation throughout the specimens in either of the two cases, although it is surmised that the distribution is more nearly uniform in the cylindrical shape.

Figures 3.2 and 3.3 show two separate recompacted clayey silt specimens after being subjected to confining pressures of 500 and 5,000 psi, respectively. Although some rebounding occurred, the general deformed shape achieved after completion of loading remained upon removal of the pressure. The shape is basically double cone with some deformation of the ends as typified in Figure I-C of Figure 3.1. Figures 3.4 and 3.5 show deformed specimens of silty clay with rock fragments after hydrostatic loading to pressures of 1,000 and 5,000 psi, respectively. Note that these specimens deformed as fairly uniform cylinders as typified in Figure II-A of Figure 3.1. All of the above specimens were tested in the same manner; thus the differences in deformed shape can only be attributed to the physical properties of the specimen material. Each type material, therefore, should be considered separately in analyses.

To illustrate the various approaches that can be used to calculate volumetric strain, consider only one of the deformed shapes as shown in Figure 3.1. In this case the specimen starts from an initial shape of a uniform right circular cylinder whose volume $V_{0}$ is 


$$
\mathrm{V}_{0}=\frac{\pi}{4}\left(\mathrm{D}_{0}\right)^{2}\left(\mathrm{H}_{0}\right)
$$

Where:

$$
\begin{aligned}
& \mathrm{D}_{\mathrm{O}}=\text { original diameter } \\
& \mathrm{H}_{\mathrm{O}}=\text { original height }
\end{aligned}
$$

The specimen then deforms as a double cone with fixed ends, i.e., shape I-B. Throughout the example, compression will be considered as positive and all strains will be calculated in Lagrangian notation, i.e. (change in dimension)/(original dimension). Raw data measurements include pressure $\mathrm{p}$, total height change $\Delta H$, and total diameter change $\Delta D$ at midheight of the specimen.

3.1.I Method V-1. In this method, the deformed shape is approximated by straight lines and hence, two truncated cones placed end to end as shown in Figure 3.6. The volume $v_{c}$ of the specimen at any given time, i.e. the current volume is

$$
V_{c}=V_{0}-\Delta V=\frac{1}{3} H_{1}\left(A_{1}+A_{0}+\sqrt{A_{1} A_{0}}\right)
$$

Where:

$$
\begin{aligned}
& \mathrm{V}_{0}=\text { initial volume }=\mathrm{H}_{0} \mathrm{~A} \\
& \mathrm{H}_{1}=\text { current height }=\mathrm{H}_{0}-\Delta \mathrm{H} \quad \pi \mathrm{D}_{1}^{2} \\
& \mathrm{~A}_{1}=\text { current area at midheight }=\frac{1}{4} \\
& \mathrm{D}_{1}=\text { current diameter at midheight }=\mathrm{D}_{0}-\Delta \mathrm{D} \\
& \mathrm{A}_{0}=\text { fixed area of ends }=\frac{\pi \mathrm{D}_{0}^{2}}{4}
\end{aligned}
$$

The volumetric strain $\frac{\Delta V}{V_{\rho}}$ can be found from

$$
\begin{aligned}
\frac{\Delta V}{V_{0}} & =\frac{V_{0}-V_{c}}{V_{0}} \\
& =\frac{\frac{\pi}{4} D_{0}^{2} H_{0}-\frac{H_{1}}{3}\left(\frac{\pi}{4}\right)\left(D_{1}^{2}+D_{0}^{2}+D_{1} D_{0}\right)}{\frac{\pi}{4} D_{0}^{2} H_{0}}
\end{aligned}
$$


Substitutions can, of course, be made to allow comparison of volumetric strain in terms of axial and radial strains, i.e.

$$
\begin{gathered}
\epsilon_{\mathrm{a}}=\operatorname{axial} \text { strain }=\frac{\Delta H}{\mathrm{H}_{0}} \\
\epsilon_{r}=\text { radial strain }=\frac{\Delta D}{\mathrm{D}_{0}} \\
\mathrm{H}_{1}=\mathrm{H}_{0}-\epsilon_{a} \mathrm{H}_{0} \\
D_{1}=\mathrm{D}_{0}-\epsilon_{r} \mathrm{D}_{0}
\end{gathered}
$$

and the volumetric strain for Method V-1 becomes

$$
\begin{aligned}
\frac{\Delta V}{V_{0}} & =\frac{D_{0}^{2} H_{0}-\left(H_{0}-\epsilon_{a} H_{0}\right) \frac{1}{3}\left[\left(D_{0}-\epsilon_{r} D_{0}\right)^{2}+D_{0}^{2}+\left(D_{0}-\epsilon_{r} D_{0}\right)\left(D_{0}\right)\right]}{D_{0}^{2} H_{0}} \\
& =\epsilon_{a}+\epsilon_{r}-\epsilon_{r} \epsilon_{a}+\frac{\epsilon_{r}^{2}}{3}\left(\epsilon_{a}-1\right)
\end{aligned}
$$

This is the method currently used to calculate the volumetric strain as presented in Figures 2.3 and 2.4 , and will be subsequently referred to as the standard method. This does not imply that it is necessarily the correct method, but rather only a standard used in this paper for comparison purposes.

3.1.2 Method V-2. In this method, the specimen is assumed to always have an average diameter of $\left(D_{0}+D_{i}\right) / 2$ as indicated in $F i g-$ ure 3.7. The volume $V_{c}$ of the specimen at any given time is

$$
\mathrm{V}_{\mathrm{c}}=\mathrm{V}_{0}-\Delta \mathrm{V}=\frac{\pi}{4}\left(\mathrm{D}_{0}-\frac{1}{2} \Delta \mathrm{D}_{1}\right)^{2} \mathrm{H}_{1}
$$


where $\Delta D_{1}=$ current total change in diameter at midheight; other notations are as before. The volumetric strain can be found from

$$
\frac{\Delta V}{V_{0}}=\frac{\frac{\pi}{4} D_{0}^{2} H_{0}-\frac{\pi}{4}\left(D_{0}-\frac{1}{2} \Delta D_{1}\right)^{2} H_{1}}{D_{0}^{2} H_{0}}
$$

Keeping the same definition of axial and radial strain, the volumetric strain for Method V-2 is expressed as

$$
\frac{\Delta V}{V_{0}}=\epsilon_{a}+\epsilon_{r}-\epsilon_{a} \epsilon_{r}+\frac{\epsilon_{r}^{2}}{4}\left(\epsilon_{a}-1\right)
$$

3.1.3 Method V-3. In this method, the midheight lateral deformation is assumed to be representative of the entire specimen as indicated in Figure 3.8. The current volume, therefore, is

$$
V_{c}=V_{0}-\Delta V=\frac{\pi}{4} D_{1}^{2} H_{1}
$$

The volumetric strain can be found from

$$
\begin{aligned}
\frac{\Delta V}{V_{0}} & =\frac{V_{0}-V_{c}}{V_{0}} \\
& =\frac{\frac{\pi}{4} D_{0}^{2} H_{0}-\frac{\pi}{4} D_{-1}^{2} H_{1}}{\frac{\pi}{4} D_{0}^{2} H_{0}}
\end{aligned}
$$

and in terms of axial and radial strains, the volumetric strain for Method V-3 is

$$
\frac{\Delta V}{V_{0}}=\epsilon_{a}+2 \epsilon_{r}-2 \epsilon_{r} \epsilon_{a}+\epsilon_{r}^{2}\left(\epsilon_{a}-1\right)
$$


3.1.4 Method V-4. In Method V-3, the current volume of the specimen was assumed to be a right circular cylinder whose diameter was equal to the midheight diameter, and the volume outside that cylinder caused by end cap friction, i.e. dead zone, was neglected. In this method, the current volume is the same, but the original volume of the specimen is corrected to reflect a loss in volume due to the previously neglected dead zone as shown in Figure 3.9. The corrected original volume $V_{0}^{1}$ of the specimen at any given time is

$$
\mathrm{V}_{0}^{\prime}=\frac{\pi}{4} \mathrm{D}_{0}^{2} \mathrm{H}_{0}-\underbrace{\left[\frac{\mathrm{H}_{1}}{3}\left(\frac{\pi}{4}\right)\left(\mathrm{D}_{1}^{2}+\mathrm{D}_{0}^{2}+\mathrm{D}_{1} \mathrm{D}_{0}\right)-\frac{\pi}{4} \mathrm{D}_{1}^{2} \mathrm{H}_{1}\right]}_{\text {Volume of Dead Zone }}
$$

The current volume of the specimen is

$$
\mathrm{V}_{\mathrm{c}}=\frac{\pi}{4}\left(\mathrm{D}_{1}\right)^{2} \mathrm{H}_{1}
$$

In this method, volumetric strain is defined as the change in volume divided by the corrected volume, or

$$
\frac{\Delta V}{V_{0}^{\prime}}=\frac{V_{0}^{1}-V_{c}}{V_{0}^{\prime}}
$$

After similar substitutions as presented in the previous methods, Method V-4 becomes

$$
\frac{\Delta V}{V_{0}}=\frac{\epsilon_{a}+\epsilon_{r}-\epsilon_{a} \epsilon_{r}-\frac{1}{3} \epsilon_{r}^{2}\left(1-\epsilon_{a}\right)}{1-\epsilon_{r}+\epsilon_{r} \epsilon_{a}+\frac{2}{3} \epsilon_{r}^{2}\left(1-\epsilon_{a}\right)}
$$

3.1.5 Method V-5. In this method, it is assumed that only an axial deformation measurement is available and also that all strains are equal during hydrostatic loading in accordance with elastic theory. 
Therefore

$$
\frac{\Delta V}{V_{0}}=3 \epsilon_{a}
$$

3.1.6 Method V-6. This method is similar to Method V-5 except that it is assumed that only a radial deformation measurement is available. Therefore

$$
\frac{\Delta V}{V_{0}}=3 \epsilon r
$$

3.1.7 Summary. Other calculation methods could be developed although each of the above six methods has been based to some extent on observed phenomena and elastic theory. In Method V-I, the volumetric strain was based on the geometric shape of the specimen. Method V-2 was based on an average deformation assuming that the radial deformation at the center is the extreme for the specimen. Method V-3 considered only the center deformation as being representative and neglected distortions due to end restraint. Method V-4 considered the specimen to be divided into two zones, a center cylindrical zone and a surrounding dead zone. Methods V-5 and V-6 are based entirely on theory of elasticity and the assumption that only one of the measured deformations is valid. The consistent Lagrangian definition given throughout the above calculations to axial and radial strains does not imply that they are true strain values nor that these strains are distributed uniformly within the specimen. The purpose of the notation was only to permit easy comparison of the different equations of volumetric strain. A summary of the methods is presented in Figure 3.10 . 


\subsection{DETERMINATION OF DEVIATOR STRESS AND STRAIN}

When the shear phase of the test is initiated, the specimen has already deformed due to the prior hydrostatic phase to one of the various shapes discussed in the previous section. From this initial condition, the specimen deforms downward axially and outward radially under the influence of increased deviator stress $\left(\sigma_{a}-\sigma_{r}\right)$. Shape is again important in quantitatively determining the strain and stress; however, it is more difficult to properly evaluate shape during the shear phase due to the formation of a complicated series of shear zones.

Various shapes observed after shear failure of both soils and soft rocks are depicted in Figure 3.1I. Shear Types IA, IB, and IC represent ductile-type failures with a bulge as the predominant feature. Shear Types IIA, IIB, and IIC typify more brittle materials with a shear plane as the predominant feature.

Type IA shows the typical bulge-type failure with the influence of end-cap friction preventing deformation of the specimen at the ends. The failure shown in IB indicates the uniform deformation expected of a ductile-type material free of end restraint. Type IC shows a semiductile material in which a bulging-type deformation dominates, 'but cracking is noted, probably due to end-cap friction causing the formation of cone-shaped zones at either end of the specimen. Type IIA is the classical type failure with a definite shear plane formed within the specimen; such a failure for a sandstone specimen sheared during a dynamic constant p-type test is shown in Figure 3.12. The failure typified by IIB indicates the influence of end-cap friction with a distinct cone or wedge formed at either or both ends of the specimen. The wedge-type failure is usually accompanied by vertical fracture zones along the axis of the specimen. Type IIC illustrates a composite type failure where the specimen, 
composed of two types of material, fails in both materials or in just the weaker material.

In Figure 3.3, the double-cone shape was shown as formed after application of a 5,000-psi hydrostatic loading to a recompacted clayey silt specimen. Figure 3.13 shows another specimen of the same material after a small increment of deviator stress has been applied subsequent to a 5,000-psi hydrostatic loading. Note the small outward bulging just starting to occur at the center of the specimen while the ends are relatively unaffected.

The next series of photographs (Figures 3.14 through 3.17) illustrates development of a Type IA failure. Several essentially identical specimens of modeling clay were first subjected to a confining pressure of 5,000 psi and then to various increments of axial deviator stress up to the peak yield strength. Figure 3.14 shows an original, undeformed specimen. Figure 3.15 shows a specimen after a small increment of axial deviator stress has been applied and removed; the center bulges outward while the ends remain unaffected. The photograph in Figure 3.16 was taken after a greater application of deviator stress; it shows that the center bulge area has increased while the ends have just started to deform. After peak yield strength has been reached, the specimen assumed the shape shown in Figure 3.17. Apparent dead zones occurred at either end of the specimen along with noticeable deformations at the quarter heights of the specimen. The nonuniform distribution of stress and strain within the specimen is obvious. The sketches in Figure 3.18 illustrate the various deformed shapes which develop during a complete triaxial shear test.

As with the case of the hydrostatic test, the deformed shape can be used as a guide to calculate the average stress and strain within the specimen. To illustrate the various methods that can be used to calculate deviator stress and strain, it will be assumed that 
measurements of deviator load, confining pressure, axial deformation, and center radial deformation are available and that the specimen exhibited a double-cone shape (Type IB) during hydrostatic loading and a bulge-type failure (Type IA) when sheared. Strains will be defined in terms of measured deformations for purposes of comparison.

$$
\epsilon_{\mathrm{a}}=\frac{\Delta \mathrm{H}_{2}}{\mathrm{H}_{\mathrm{o}}}
$$

Where:

$$
\begin{gathered}
\Delta \mathrm{H}_{2}=\text { change in height measured during shear phase } \\
\epsilon_{r}=\frac{\Delta \mathrm{D}_{2}}{\mathrm{D}_{0}}
\end{gathered}
$$

Where:

$\Delta D_{2}=$ change in midheight diameter measured during shear phase $\mathrm{H}_{\mathrm{O}}$ and $\mathrm{D}_{\mathrm{O}}$ are the original prehydrostatic phase height and diameter, respectively, so that the total strain from the start of the hydrostatic phase to some point of interest during the shear phase can be found by algebraic addition of the strains from both phases. The radial strain during the shear phase is negative since it will be an outward movement.

3.2.I Method S-1. In this method, it is assumed that the axial strain and the radial strain as calculated from the vertical displacement of the top cap and the midheight radial deflection completely represent the actual strains occurring within the specimen. Figure 3.19 shows the assumed deformed shape at the start of the shear test and during the shear test. The deviator strain becomes

$$
\epsilon_{\mathrm{a}}-\epsilon_{\mathrm{r}}=\frac{\Delta \mathrm{H}_{2}}{\mathrm{H}_{\mathrm{o}}}-\left(\frac{-\Delta \mathrm{D}_{2}}{\mathrm{D}_{\mathrm{o}}}\right)
$$

and the deviator stress is 


$$
\sigma_{a}-\sigma_{r}=\frac{4 \mathrm{P}}{\pi\left(D_{2}\right)^{2}}
$$

Where:

$$
\mathrm{D}_{2}=\text { current diameter during shear test }
$$

This method was used to calculate the deviator stress and strain results shown in Figures 2.3 and 2.4 and will subsequently be referred to in this paper as the "standard" method for comparison purposes. 3.2.2 Method S-2. For this method, assume that the axial deformation is representative, but that the center radial deformation is a maximum value and therefore not representative of the entire specimen. The radial deformation should therefore be weighted, and for simplicity, an average value of one-half is used as shown in Figure 3.20. The deviator strain becomes

$$
\epsilon_{a}-\epsilon_{r}=\frac{\Delta H_{2}}{H_{0}}-\left(\frac{1}{2} \frac{-\Delta D_{2}}{D_{0}}\right)
$$

and the deviator stress is

$$
\sigma_{a}-\sigma_{r}=\frac{4 \mathrm{P}}{\pi\left(D_{1}+\frac{1}{2} \Delta D_{2}\right)^{2}}
$$

Where:

$D_{1}=$ Deformed diameter at the end of the hydrostatic phase 3.2.3 Method $\mathrm{S}-3$. In this method, it is assumed that only the axial measurement is available and that the ratio of radial strain to axial strain is equal to -0.5 in accordance with elastic theory for pure shear. The deviator strain is therefore

$$
\epsilon_{\mathrm{a}}-\epsilon_{\mathrm{r}}=\frac{\Delta \mathrm{H}_{2}}{\mathrm{H}_{0}}-\left(-0.5 \frac{\Delta \mathrm{H}_{2}}{\mathrm{H}_{0}}\right)
$$


and the deviator stress is

$$
\sigma_{a}-\sigma_{r}=\frac{4 P}{\pi\left[D_{0}\left(1+\frac{1}{2} \epsilon_{a}\right)-\Delta D_{1}\right]^{2}}
$$

3.2.4 Method $\mathrm{S}-4$. This method is derived based on the assumptions that only the measured axial deformation is valid and that no volume change occurs during the shear phase. This method is commonly used in soil mechanics where only axial deflection is measured. The specimen is assumed to undergo cylindrical deformation as shown in Figure 3.21 with no change in volume. Because it is assumed that there is no volume change during shear, the current diameter during the shear test $D_{2}$ can be expressed as

$$
D_{2}=\sqrt{\frac{4}{\pi}\left(\frac{V_{1}}{\mathrm{H}_{2}}\right)}
$$

and the radial strain can be calculated as

$$
\begin{aligned}
\epsilon_{r} & =\frac{D_{1}-D_{2}}{D_{0}} \\
& =\frac{D_{1}-\sqrt{\frac{4}{\pi}\left(\frac{V_{1}}{H_{2}}\right)}}{D_{0}}
\end{aligned}
$$

Where:

$$
\begin{aligned}
& \mathrm{V}_{1}=\text { deformed volume at the end of the hydrostatic phase } \\
& \mathrm{H}_{2}=\text { current height during shear phase }
\end{aligned}
$$

The deviator strain is therefore

$$
\epsilon_{\mathrm{a}}-\epsilon_{\mathrm{r}}=\frac{\Delta \mathrm{H}_{2}}{\mathrm{H}_{0}}-\left[\frac{\mathrm{D}_{1}-\sqrt{\frac{4}{\pi}\left(\frac{\mathrm{V}_{1}}{\mathrm{H}_{2}}\right)}}{\mathrm{D}_{0}}\right]
$$


and the deviator stress is found from

$$
\sigma_{\mathrm{a}}-\sigma_{r}=\frac{\mathrm{PH}_{2}}{\mathrm{~V}_{1}}
$$

3.2.5 Method $S-5$. In this method, as in Method $S-4$, it is assumed that there is no volume change, but in this case the axial deflection is assumed to be invalid so that only the radial deformation is available for calculation purposes. The volume of the specimen,at the end of the hydrostatic test $\mathrm{V}_{1}$ and the current diameter during the shear phase $\mathrm{D}_{2}$ may be used to calculate an assumed current height during the shear phase $\mathrm{H}_{2}^{\prime}$ for a right circular cylindrical specimen, i.e.

$$
H_{2}^{\prime}=\frac{12}{\pi} \frac{V_{1}}{D_{2}^{2}+D_{0}^{2}+D_{0} D_{2}}
$$

The axial and radial strains may be expressed as

$$
\begin{gathered}
\epsilon_{a}=\frac{\mathrm{H}_{1}-\frac{12}{\pi} \frac{\mathrm{V}_{1}}{\mathrm{D}_{0}^{2}+\mathrm{D}_{2}^{2}+\mathrm{D}_{0} \mathrm{D}_{2}}}{\mathrm{H}_{0}} \\
\epsilon_{r}=\frac{\Delta \mathrm{D}_{2}}{\mathrm{D}_{0}}
\end{gathered}
$$

The deviator strain is therefore

$$
\epsilon_{a}-\epsilon_{r}=\frac{\mathrm{H}_{1}-\frac{12}{\pi} \frac{\mathrm{V}_{1}}{\mathrm{D}_{0}^{2}+\mathrm{D}_{2}^{2}+\mathrm{D}_{0} \mathrm{D}_{2}}}{\mathrm{H}_{0}}-\left(\frac{-\Delta_{2}}{\mathrm{D}_{0}}\right)
$$


and the deviator stress is

$$
\sigma_{a}-\sigma_{r}=\frac{4 \mathrm{P}}{\pi\left(D_{2}\right)^{2}}
$$

3.2.6 Method $\mathrm{S}-6$. For this method, it is assumed that the axial strain as calculated from the measured change in specimen height is not representative of the axial strains within the specimen and that the change in height measurement should be corrected by some empirical factor. An arbitrary factor of 2 is used for illustration purposes. The deviator strain in this case is

$$
\epsilon_{\mathrm{a}}-\epsilon_{\mathrm{r}}=2 \frac{\Delta \mathrm{H}_{2}}{\mathrm{H}_{0}}-\left(\frac{-\Delta \mathrm{D}_{2}}{\mathrm{D}_{0}}\right)
$$

and the deviator stress becomes

$$
\sigma_{a}-\sigma_{r}=\frac{4 P}{\pi\left(D_{2}\right)^{2}}
$$

3.2.7 Summary. The above six methods represent various procedures for calculating stress and strain in soil specimens during the shear phase of triaxial tests. In Method S-I, stress and strain were based on actual measurements of applied loads, displacement of the top cap, and midheight diameter changes. Method s-2 was based on a representative diameter as the average of a fixed end diameter and the measured diameter at the center of the specimen. Method S-3 is based on an assumed strain ratio of -0.5 for elastic pure shear and the assumption that only the axial deformation measurements are valid. For-both Methods S-4 and S-5, it was assumed that no volume change occurs during the shear phase. Method s-4 required the use of only the axial measurement for calculations; Method S-5 required only the use of the radial measurement. Method S-6 was an attempt to correct the axial 
deformation by means of an arbitrary empirical factor based on limited research conducted on the distribution of axial deformation of undisturbed specimens during the shear phase. In general, the greatest axial strain seems to occur near the midheight of the specimen as illustrated in Figure 3.22. All six methods discussed in this section are summarized in Figure 3.23 . 


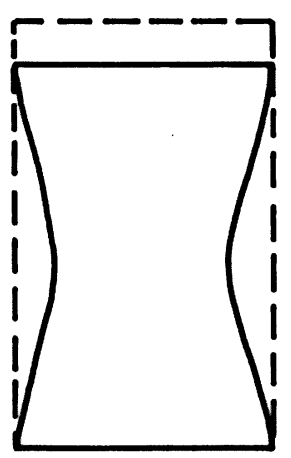

$\underline{A}$

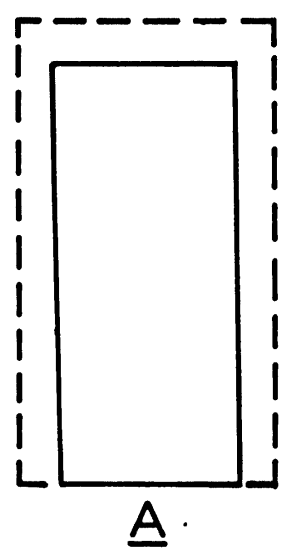

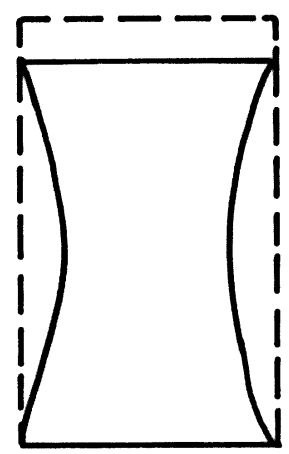

B

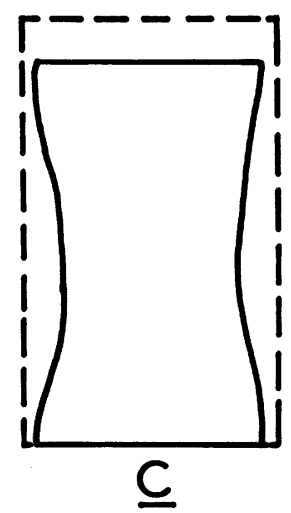

\section{DOUBLE CONE SHAPE}

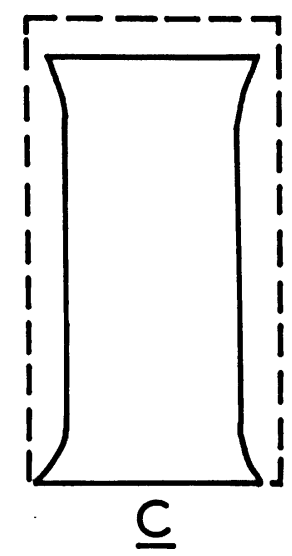

\section{CYLINDRICAL SHAPE}

\section{- - ORIGINAL SHAPE}

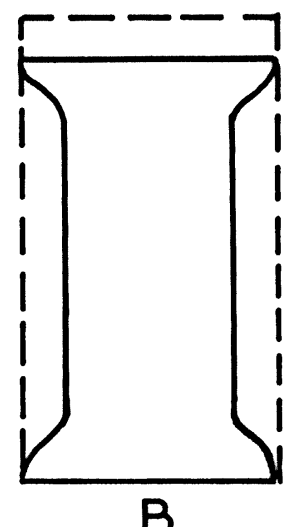

- DEFORMED SHAPE

Figure 3.1 Deformed shapes of specimens during hydrostatic loading. 


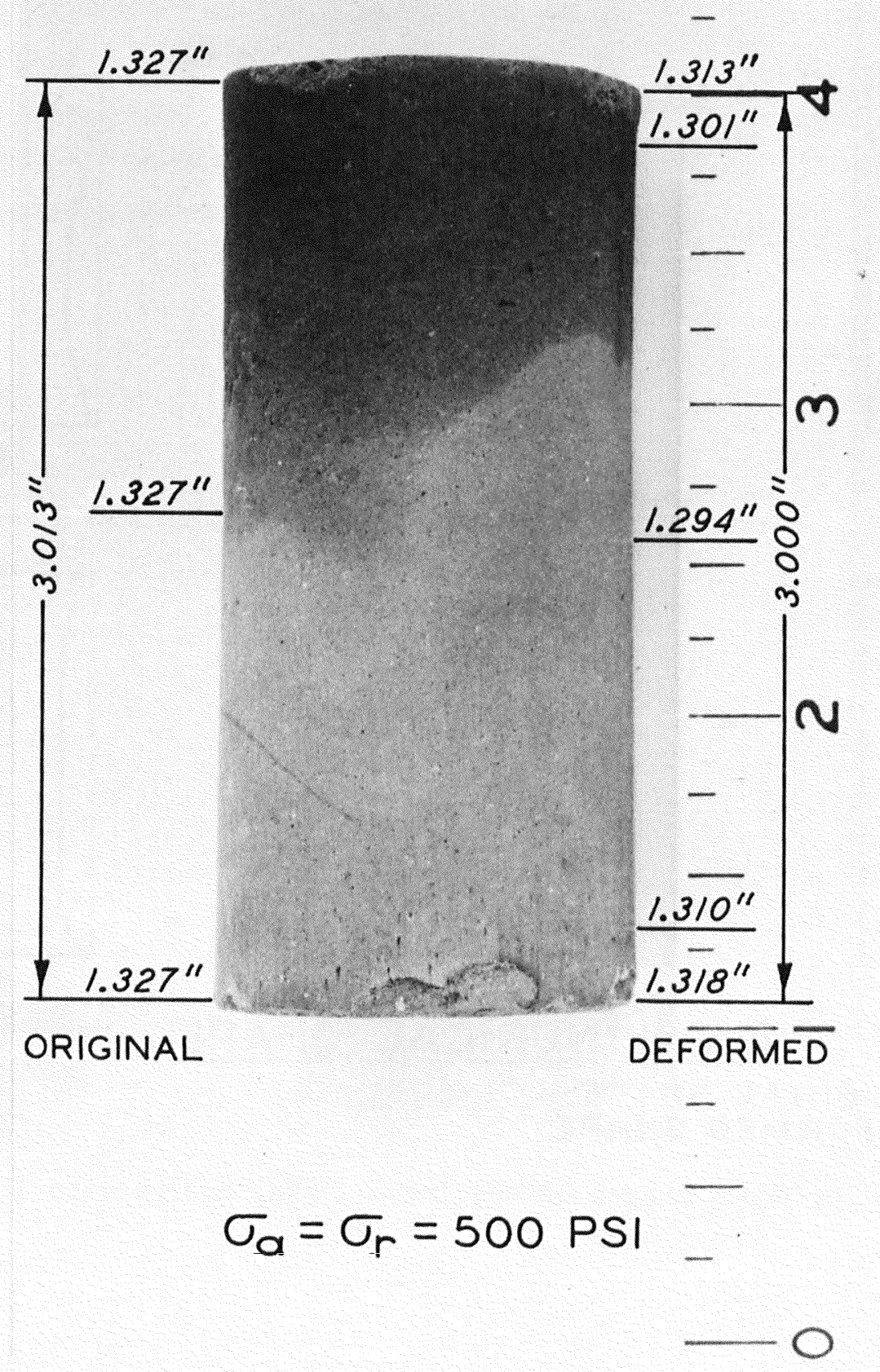

Figure 3.2 Triaxial specimen of recompacted clayey silt after being subjected to 500-psi hydrostatic pressure, shape IC. 

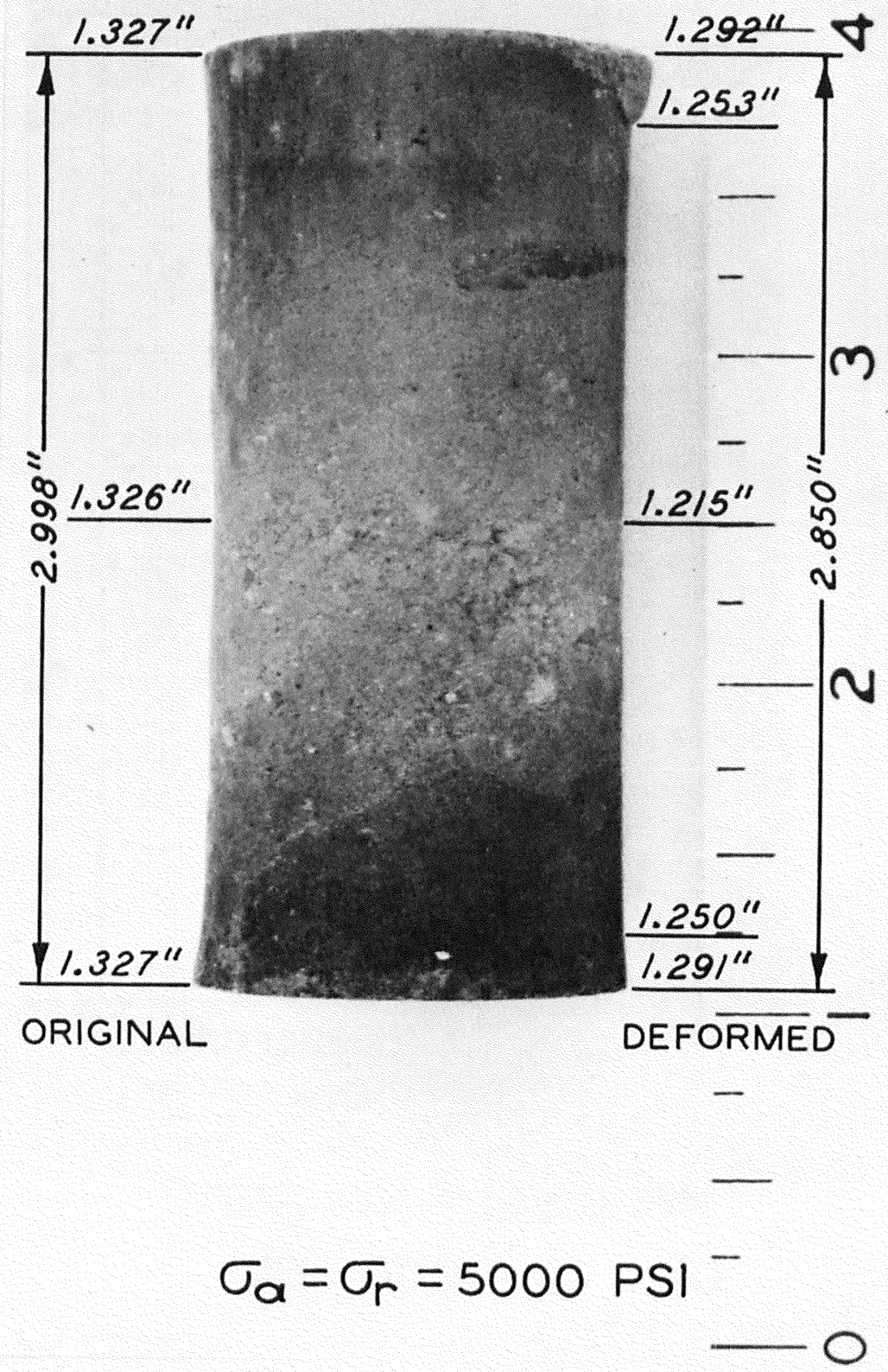

Figure 3.3 Triaxial specimen of recompacted clayey silt after being subjected to 5,000-psi hydrostatic pressure, shape IC. 


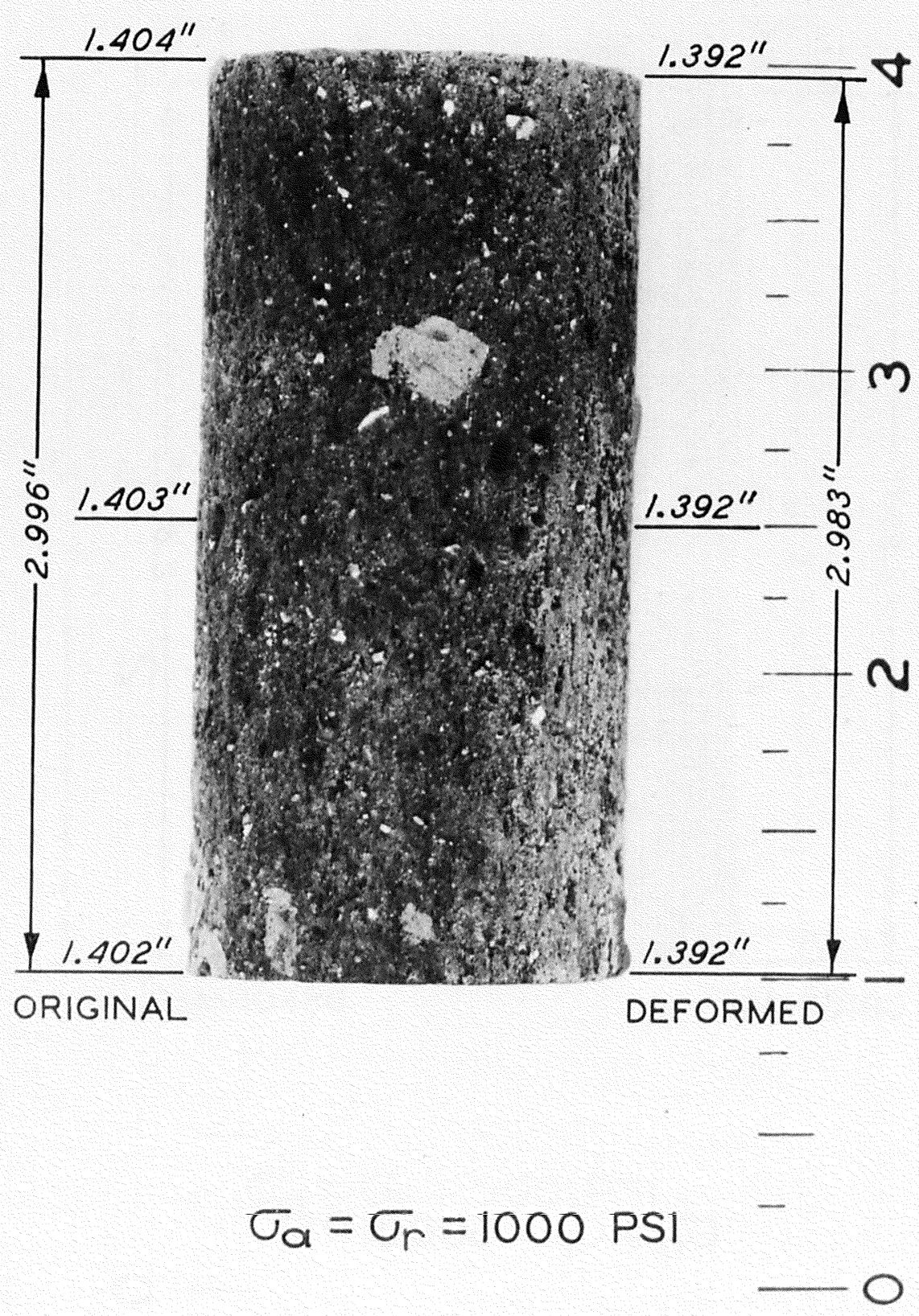

Figure 3.4 Triaxial specimen of a silty clay with rock fragments after being subjected to 1,000-psi hydrostatic pressure, shape IIA. 


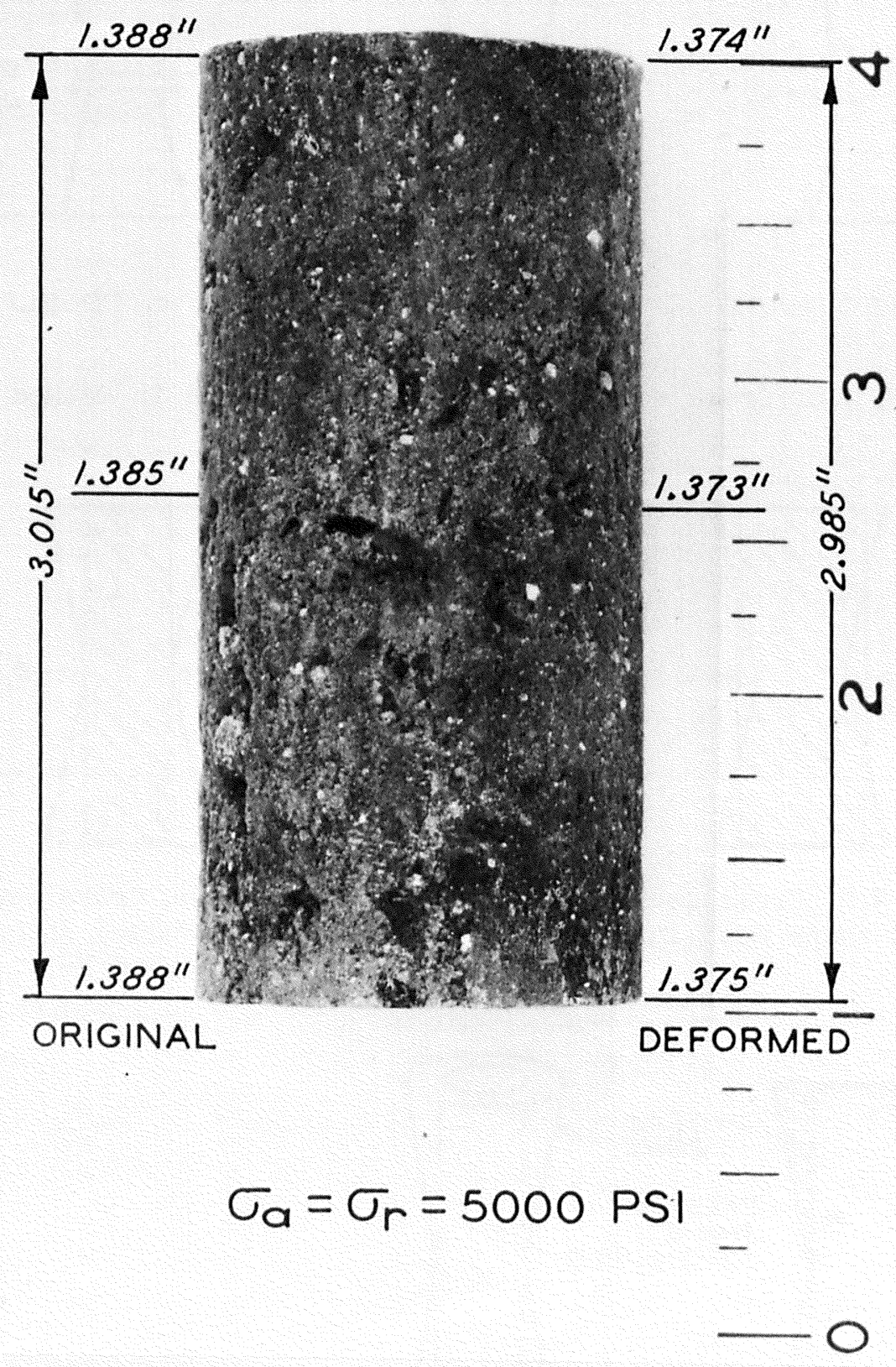

Figure 3.5 Triaxial specimen of silty clay with rock fragments after being subjected to 5,000-psi hydrostatic pressure, shape IIA. 


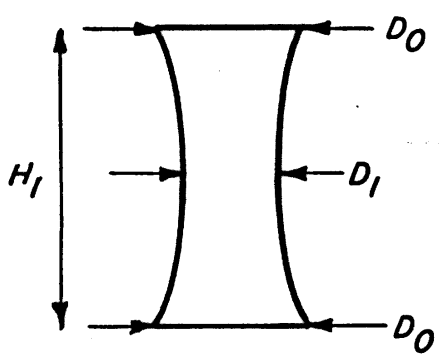

a. DEFORMED SHAPE

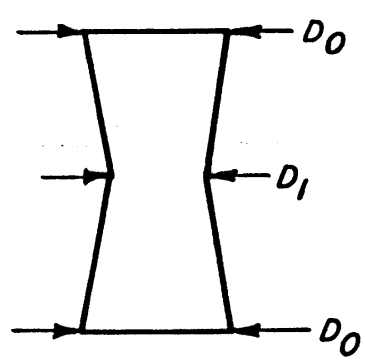

b. ASSUMED DEFORMED SHAPE

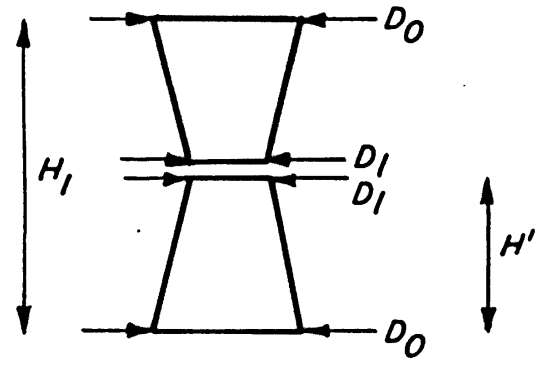

c. DOUBLE CONE

Figure 3.6 Cross section of shapes considered in Method V-1.

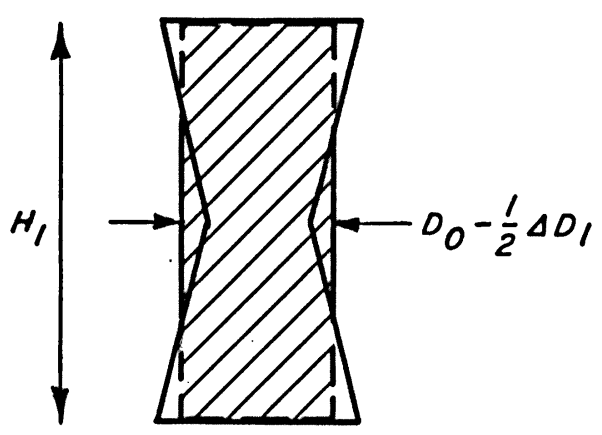

Figure 3.7 Cross section of assumed shape used in Method $\mathrm{V}-2$.

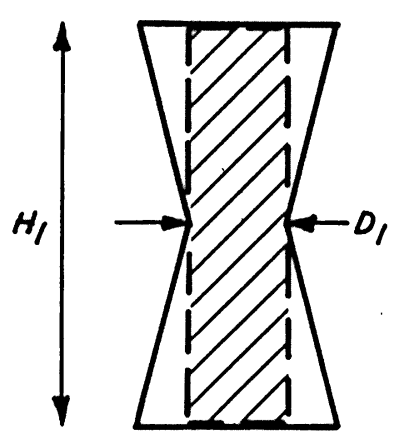

Figure 3.8 Cross section of assumed shape used in Method V-3.

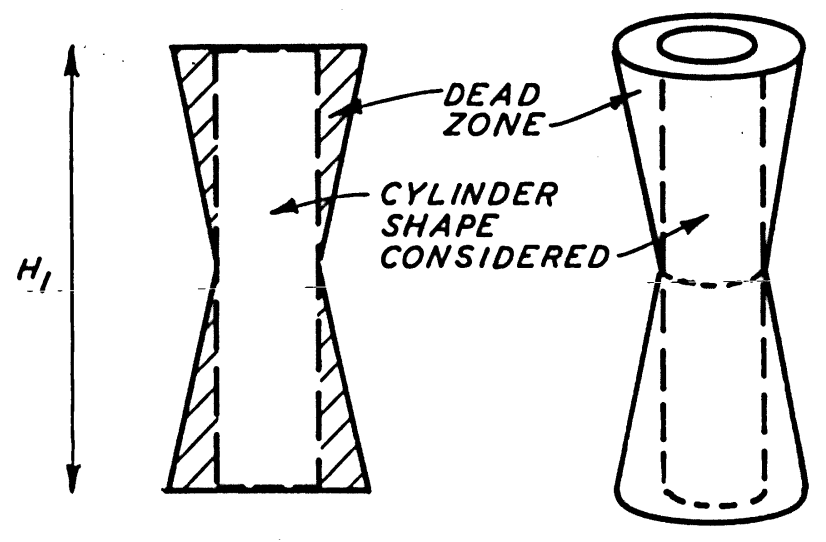

a. CROSS SECTION

b. ISOMETRIC

Figure 3.9 Assumed shape used in Method V-4. 


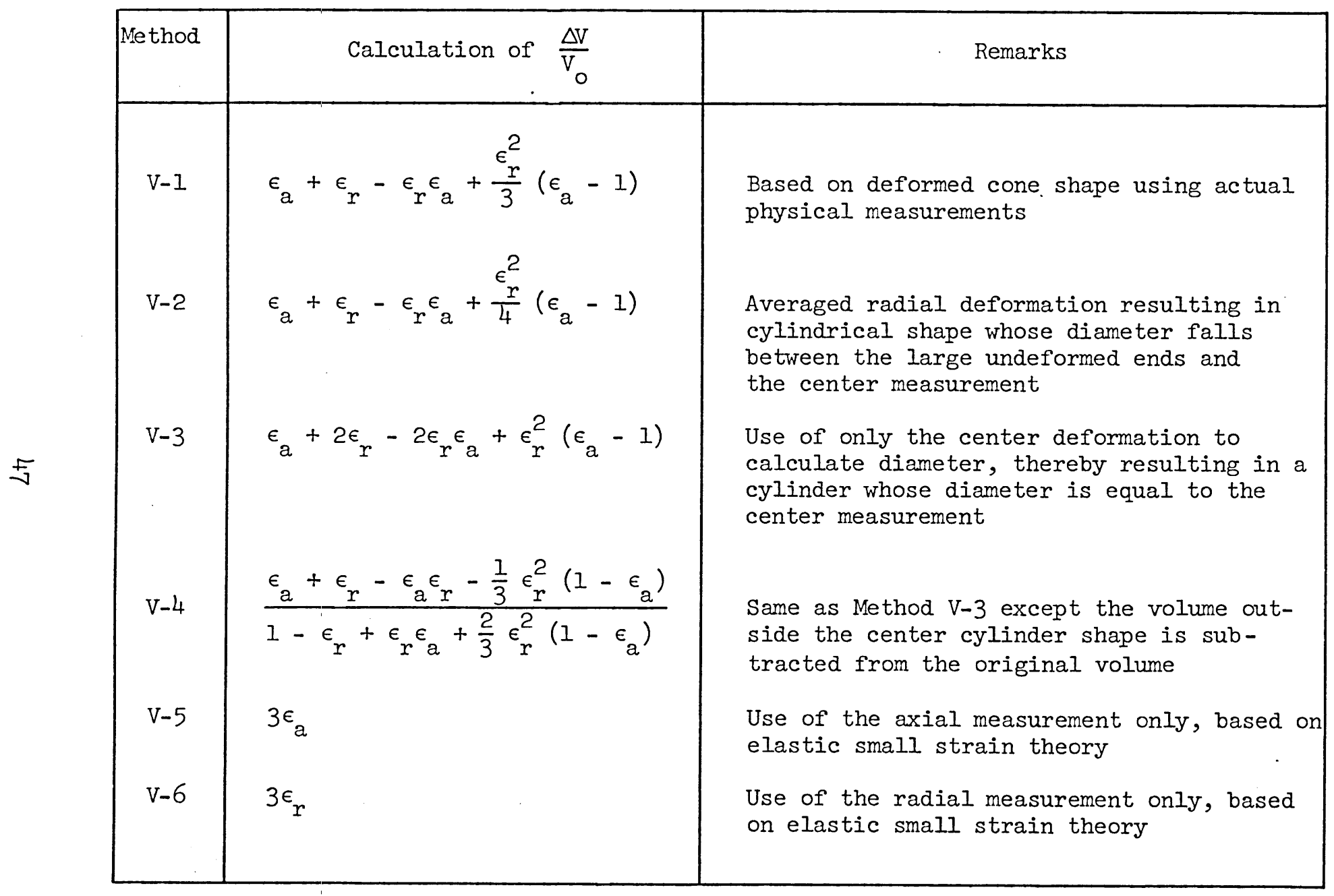

Figure 3.10 Summary of methods used to calculate volumetric strain. 

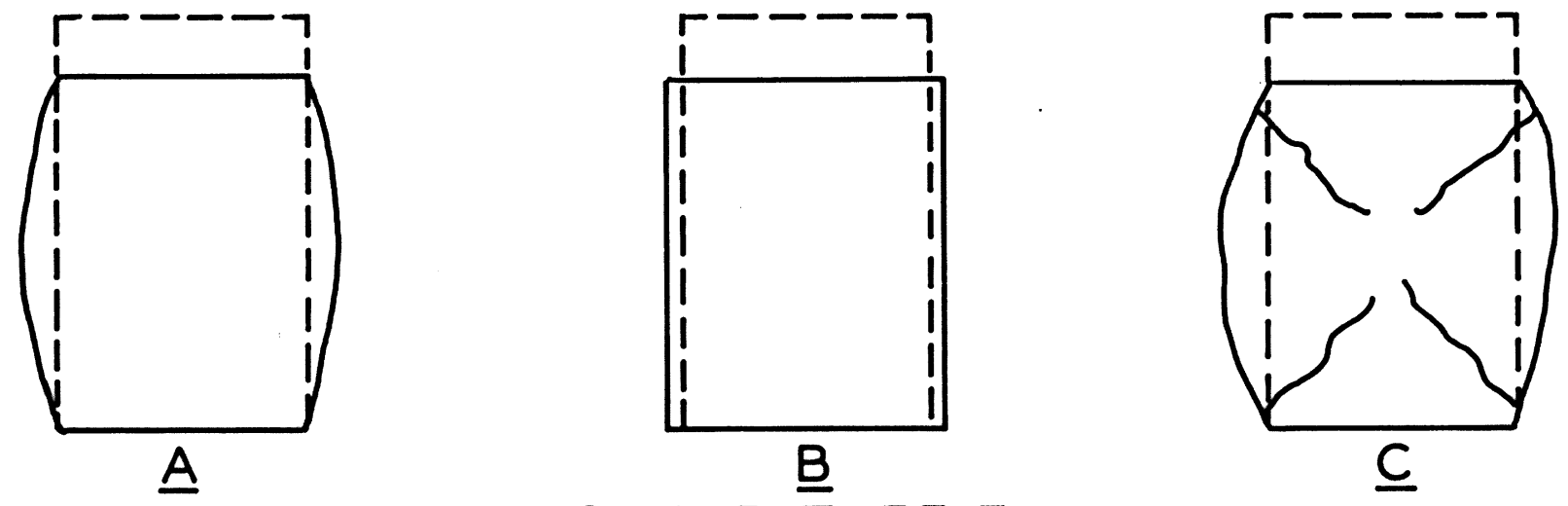

SHEAR TYPE I
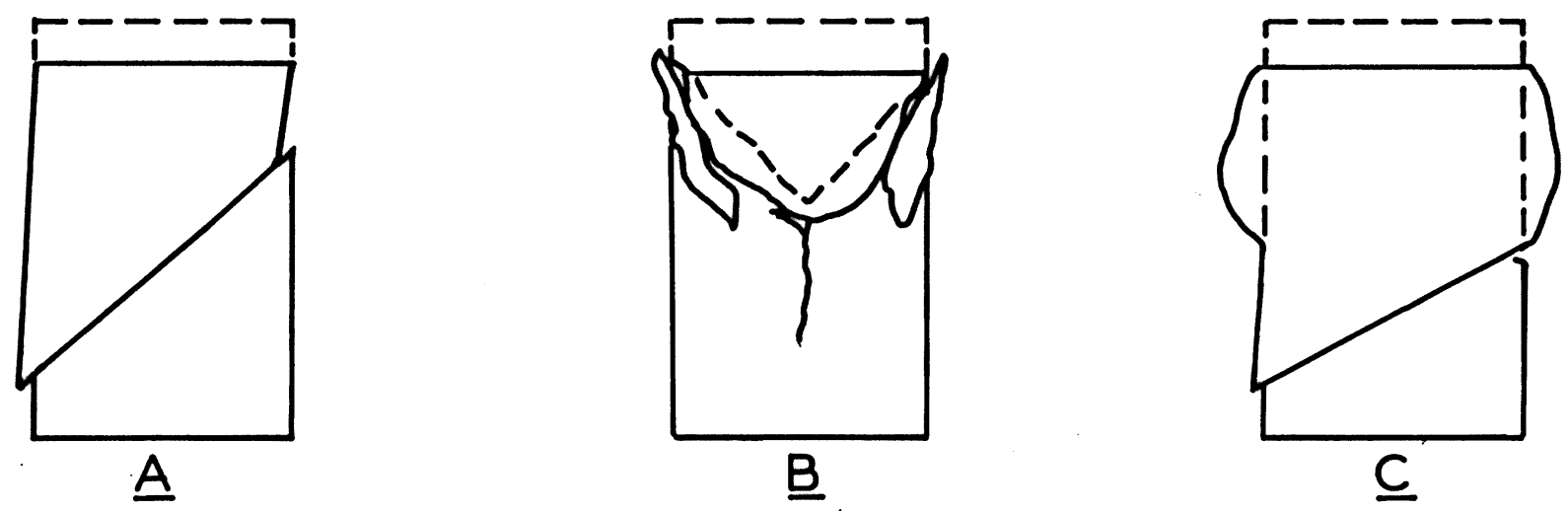

SHEAR TYPE II

--- ORIGINAL SHAPE

- DEFORMED SHAPE

Figure 3.11 Shapes of failed specimens after shear test. 


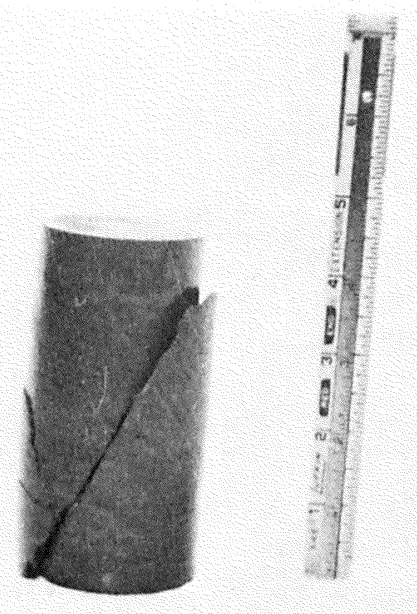

a. Specimen as removed from test device.

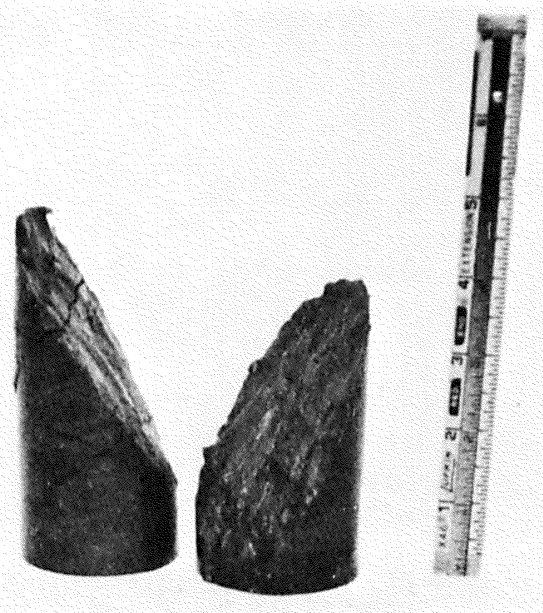

b. Specimen separated to show shear plane.

Figure 3.12 Triaxial specimen of sandstone after shear failure during a dynamic constant p-type test, shape IIA. 

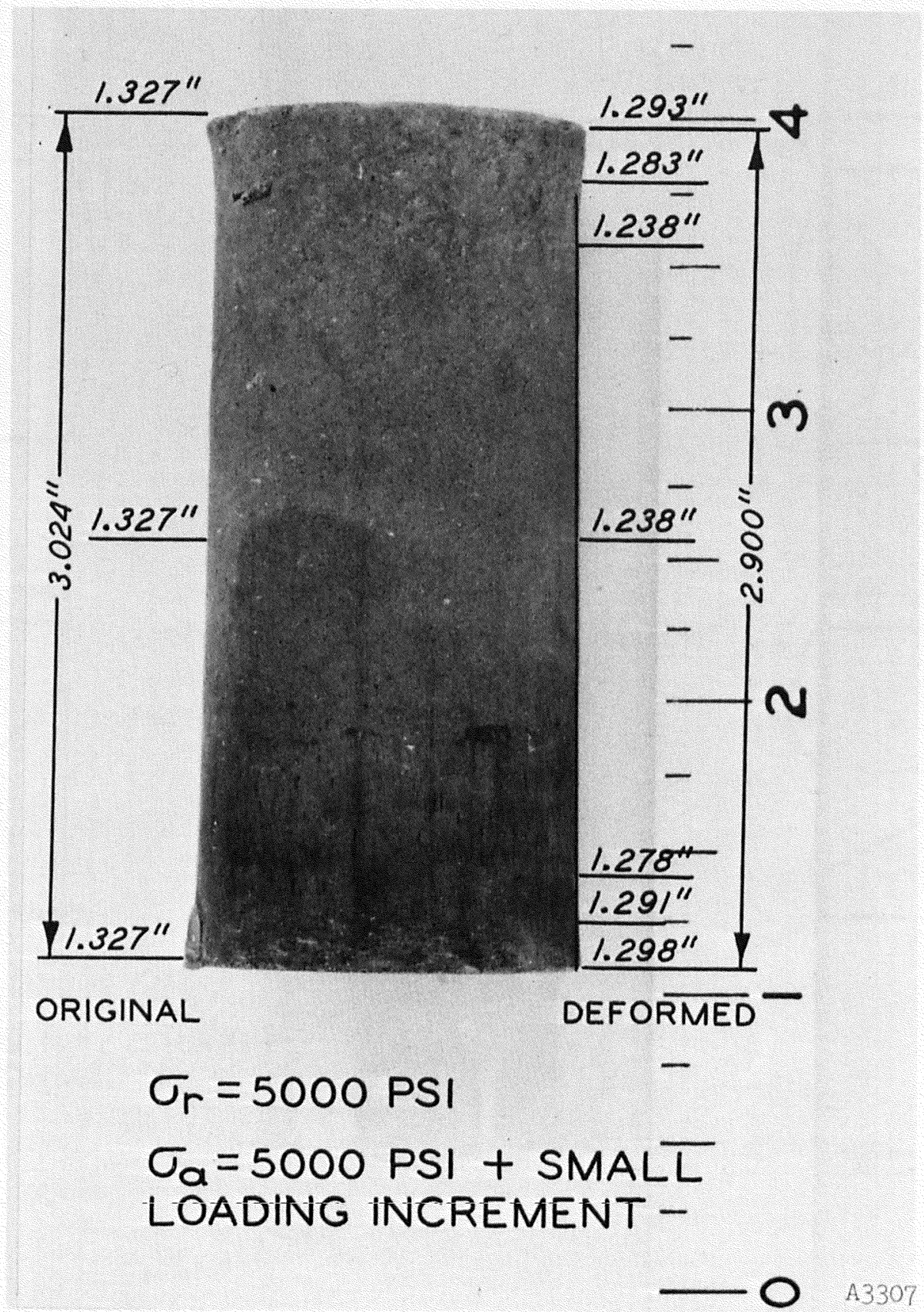

Figure 3.13 Triaxial specimen of recompacted clayey silt after being subjected to a small deviator stress while maintaining a confining pressure of 5,000 psi. 


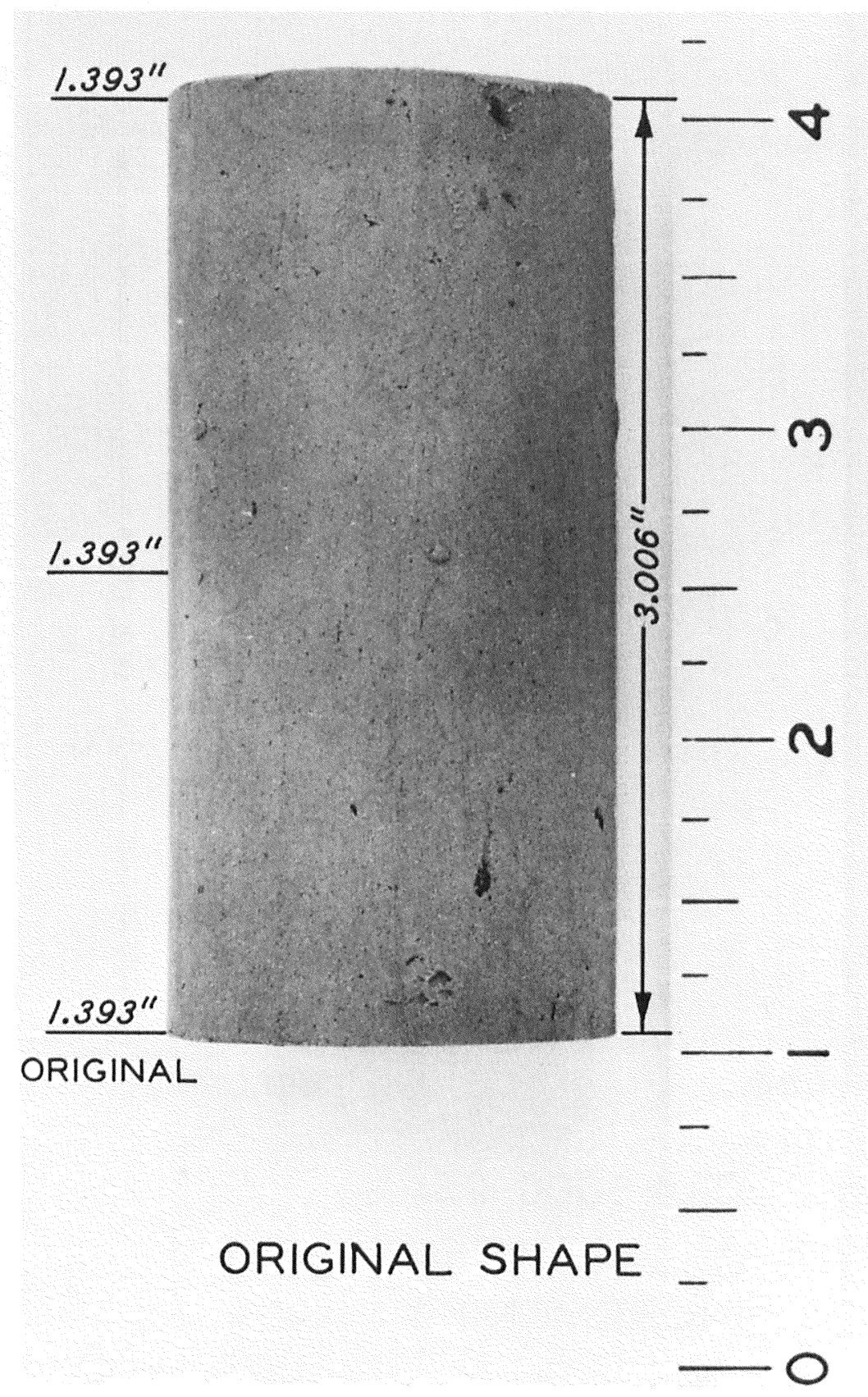

Figure 3.14 Triaxial specimen of modeling clay prior to test. 


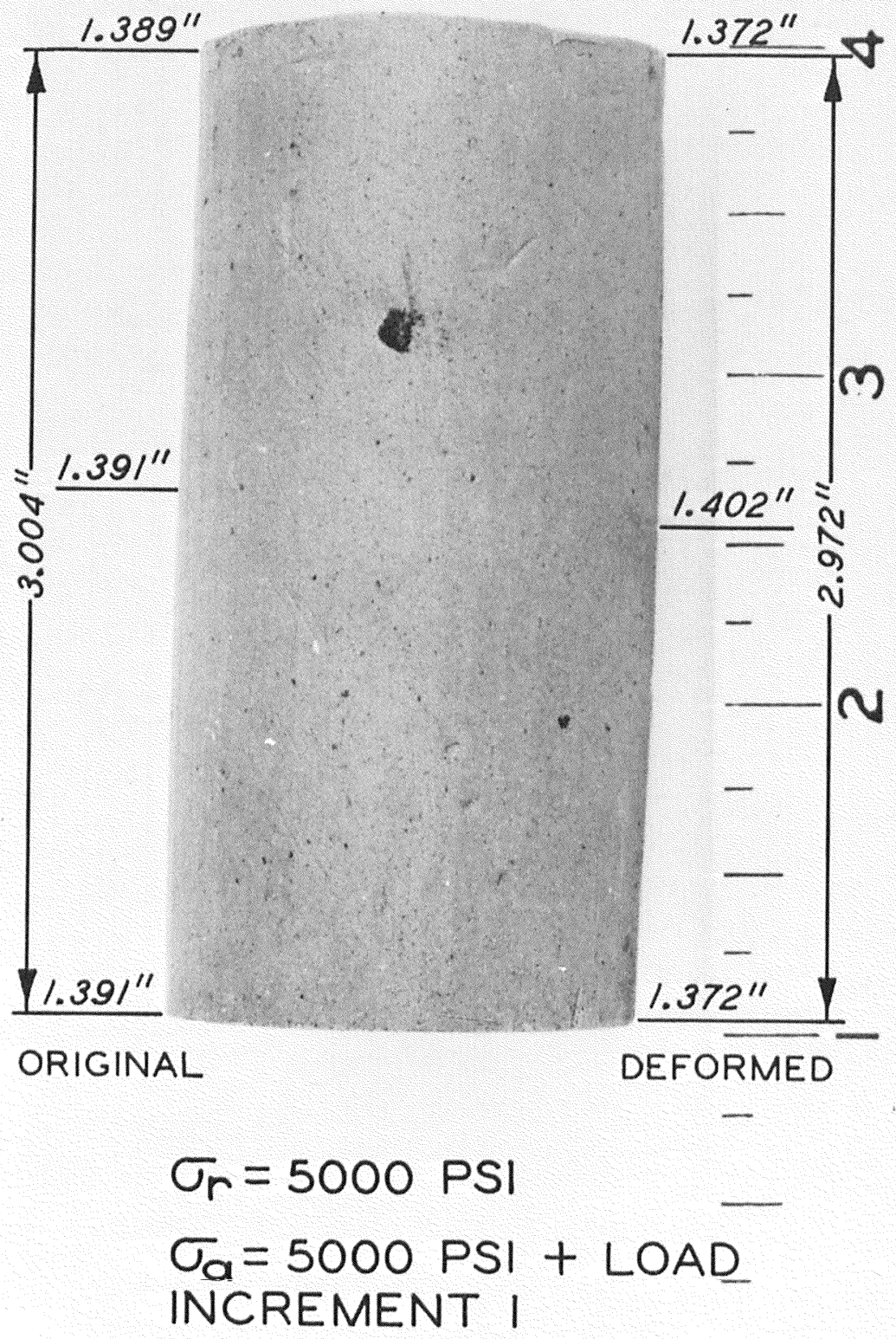

Figure 3.15 Triaxial specimen of modeling clay after application of a small deviator stress while a confining pressure of 5,000 psi is maintained. 


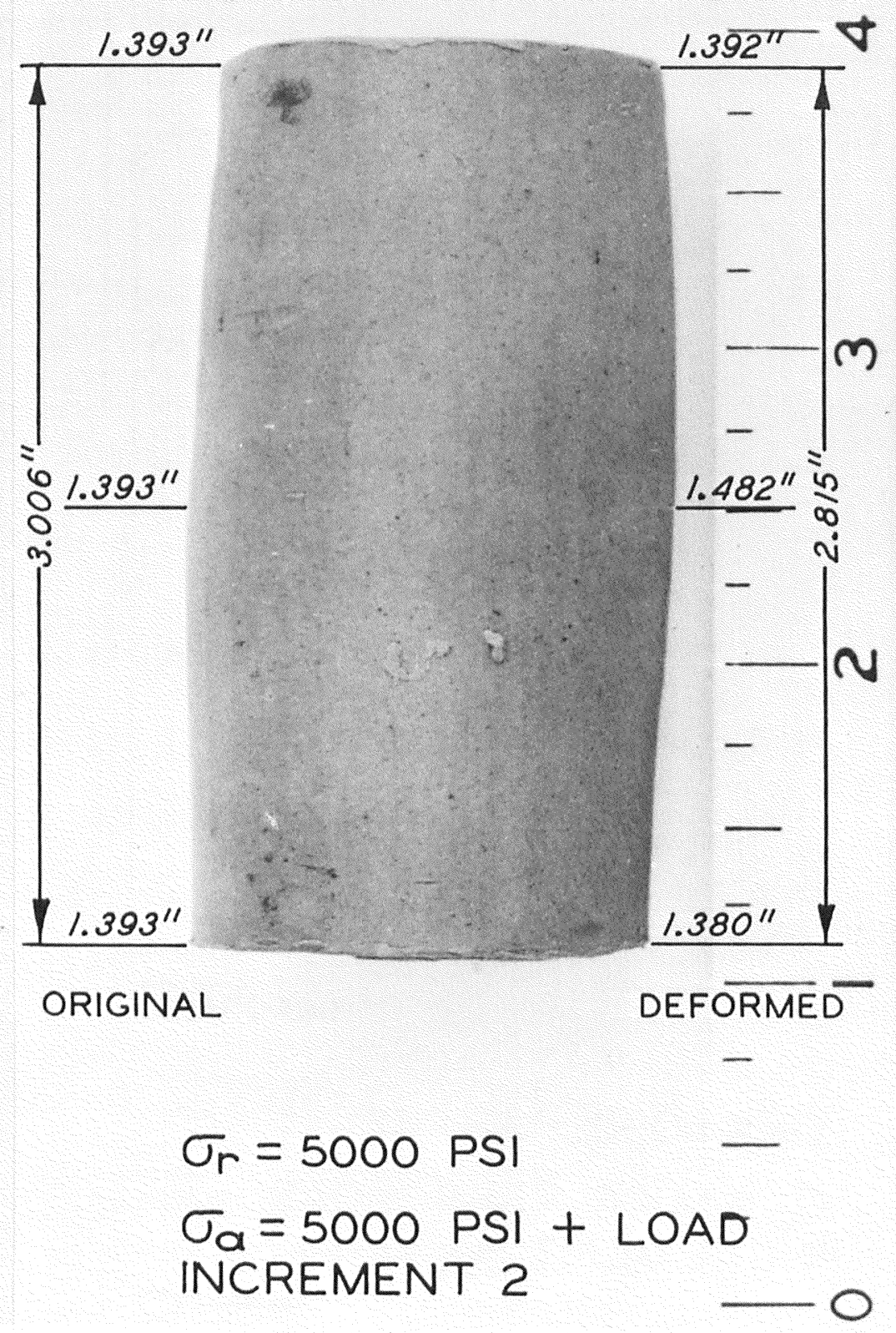

Figure 3.16 Triaxial specimen of modeling clay after application of a larger deviator stress while a confining pressure of 5,000 psi is maintained. 


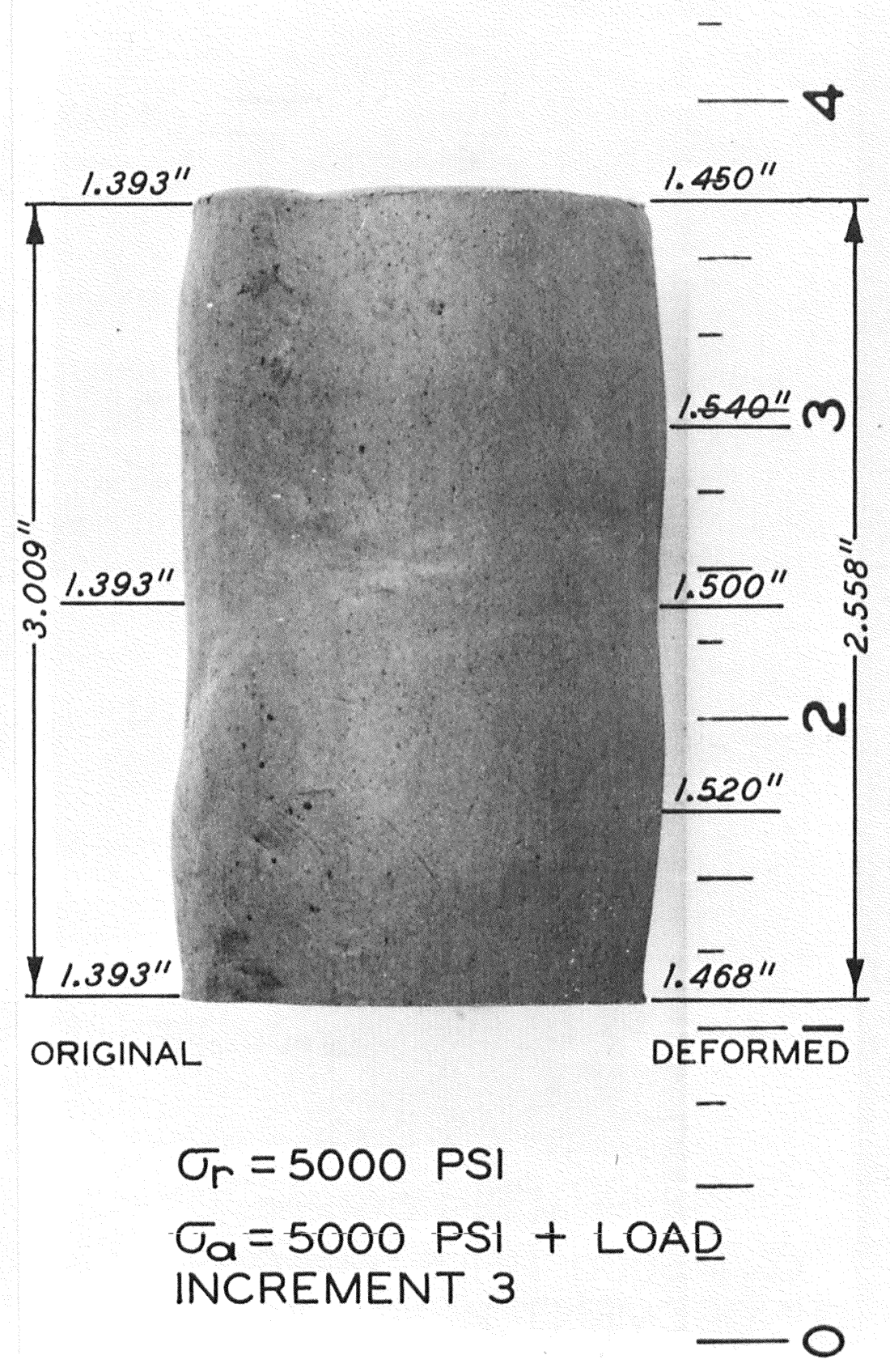

Figure 3.17 Triaxial specimen of modeling clay after application of large (postyield) deviator stress while a confining pressure of 5,000 psi is maintained. 


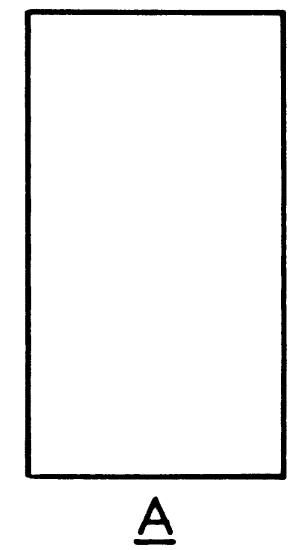

ORIGINAL SHAPE

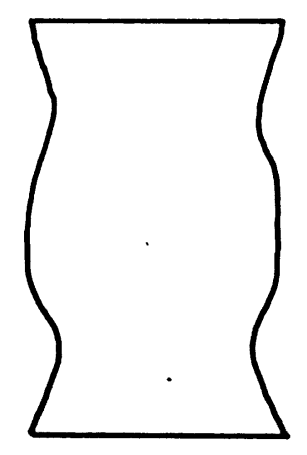

$\underline{D}$

ARGER

INCREMENT

OF LOADING

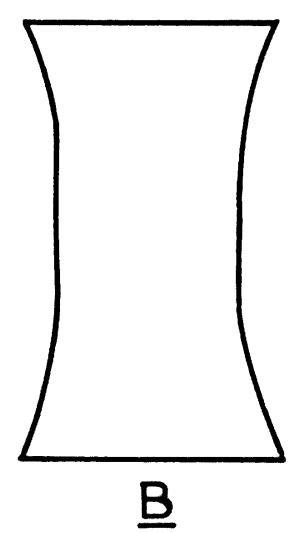

END OF HYDROSTATIC TEST

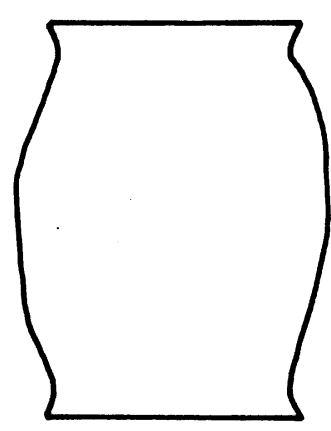

$E$

AT OR NEAR

YIELD STRENGTH

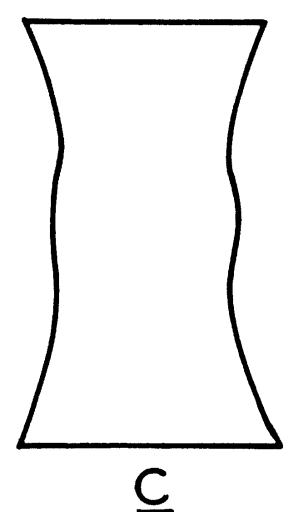

START OF

SHEAR TEST

WITH SMALL

AXIAL LOADING

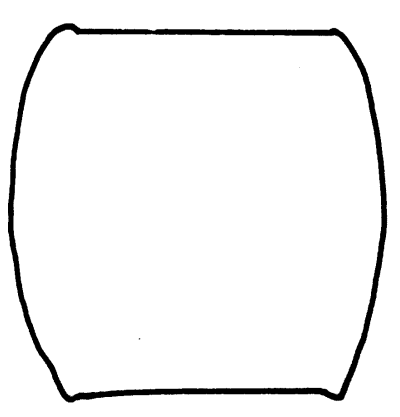

POSTYIELD

Figure 3.18 Specimen deformation during shear test. 


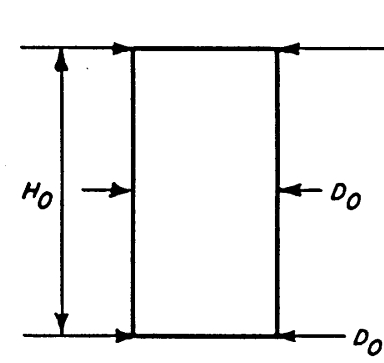

a. ORIGINAL SHAPE

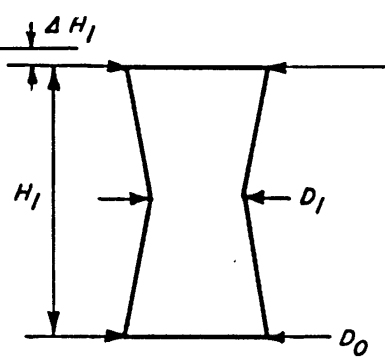

b. DEFORMED SHAPE AT END OF HYDRO

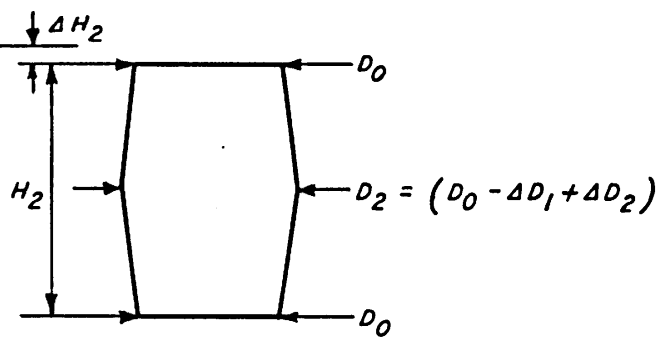

c. DEFORMED SHAPE DURING SHEAR

Figure 3.19 Cross section of specimen showing assumed deformed shapes considered in Method S-1.

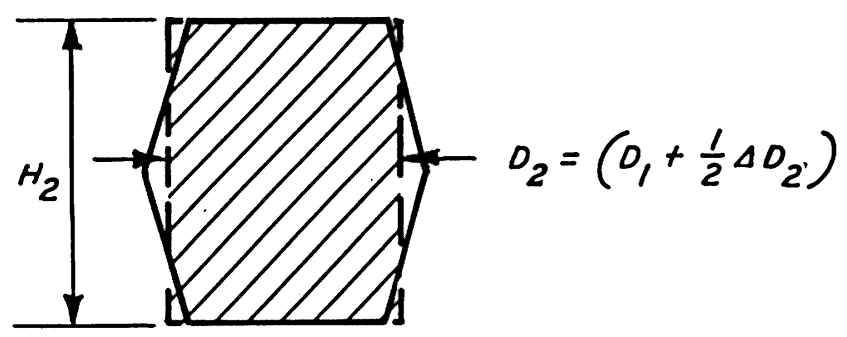

Figure 3.20 Cross section of assumed deformed shape considered in Method S-2.

Figure 3.21 Cross section of assumed deformed shape considered in Method $\mathrm{S}-4$.
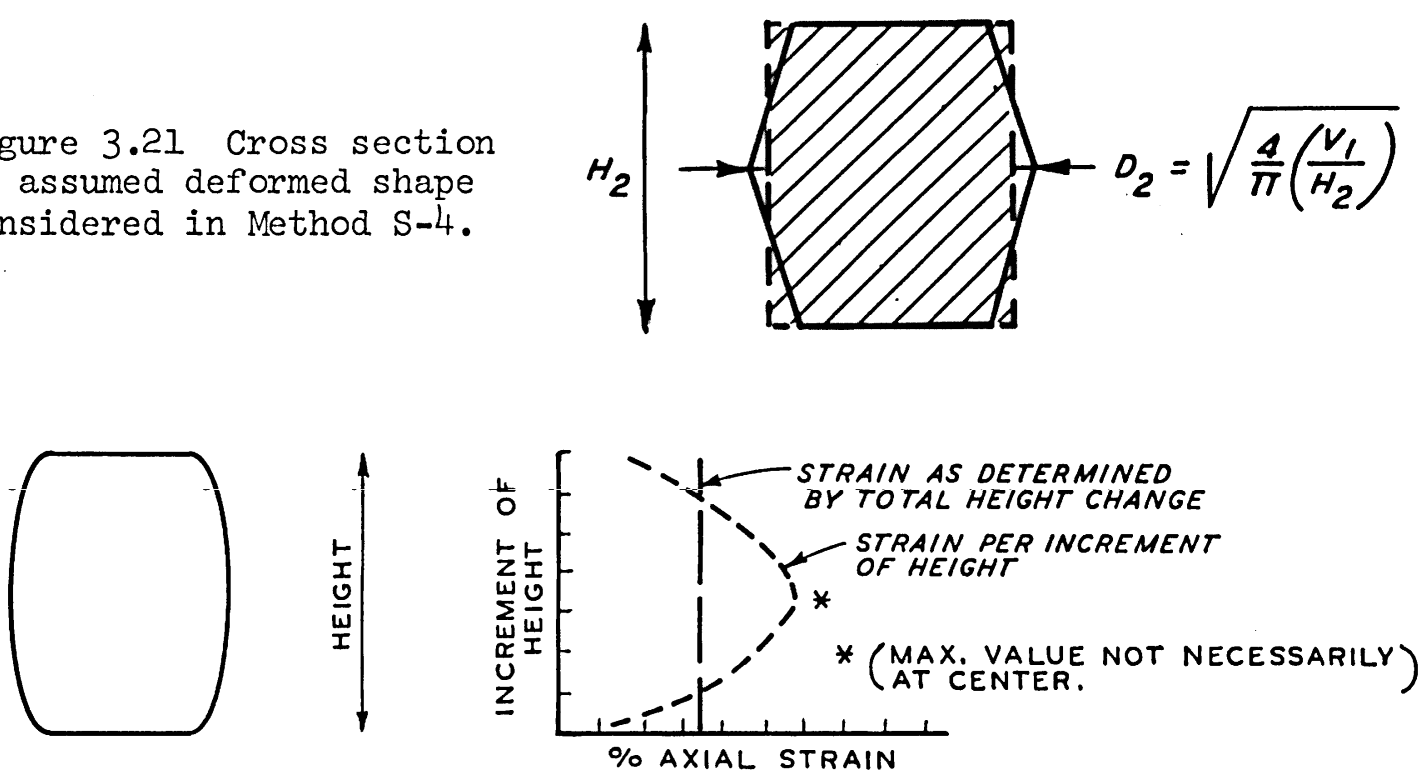

a. DEFORMED SHAPE

b. DISTRIBUTION OF AXIAL STRAIN

Figure 3.22 Distribution of axial strain along length of a specimen. 


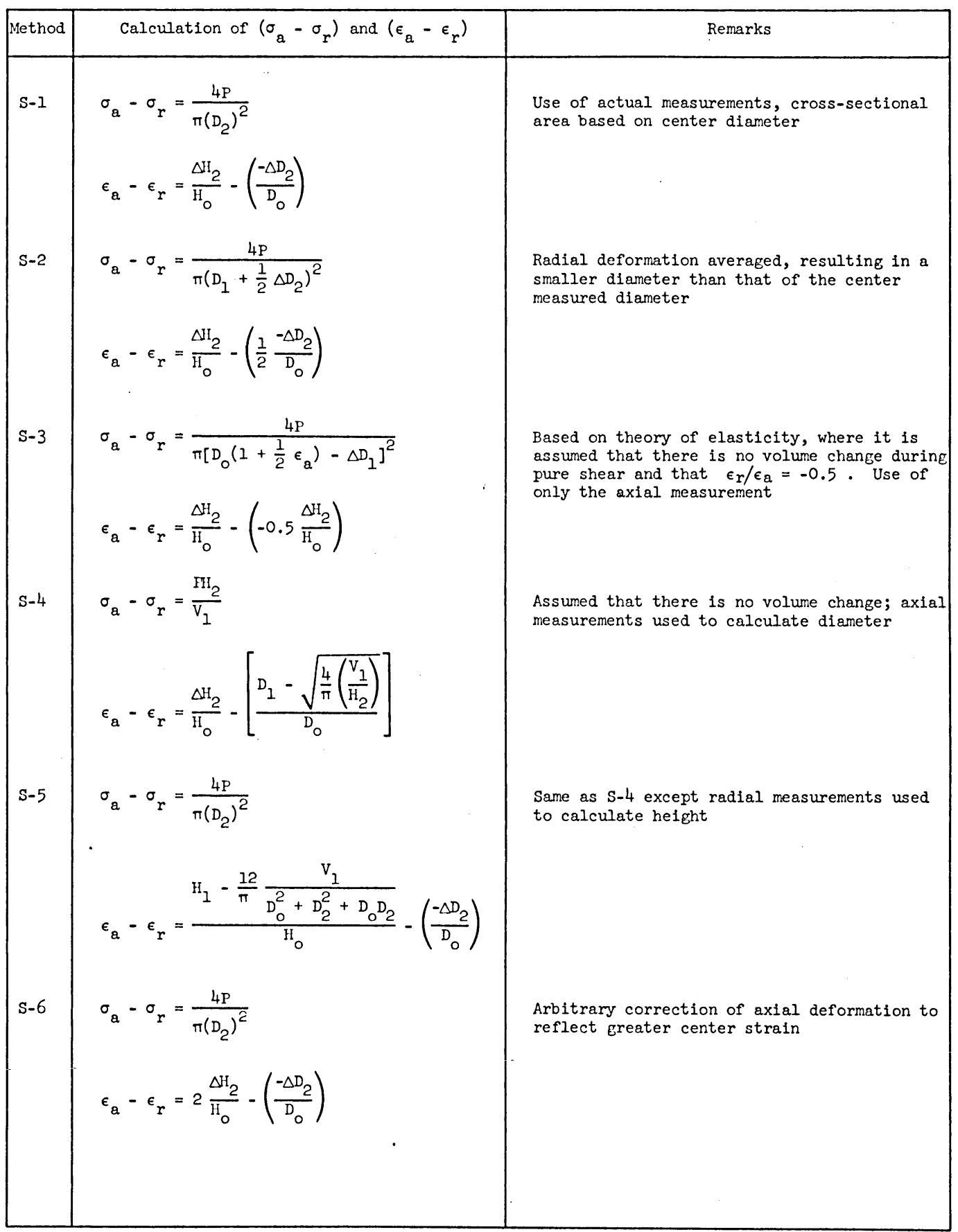

Figure 3.23 Summary of methods used to calculate deviator stress and strain. 
CHAPTER 4

DISCUSSION OF INTERPRETATION METHODS

As described in Chapter 3, various methods can be used to calculate stress and strain from load and deformation measurements obtained during triaxial tests. The differences between each method can probably best be illustrated by stress-strain curves calculated from raw test data obtained from two extremely different undisturbed specimens, i.e. one quite soft and one very stiff. The soft specimen, the sandy clay previously described in Figure 2.3, was subjected to a hydrostatic loading of 1,000 psi and then carried to failure in shear while the mean normal stress remained constant. The stiff specimen, the siltstone previously described in Figure 2.4, was subjected to a hydrostatic loading of 1,500 psi and then carried to failure in shear while the confining pressure was held constant. Measurements made for both tests included confining pressure, axial load, change in height, and change in midheight diameter. A double-cone deformed shape best approximated the response of both specimens during the hydrostatic test, followed by a bulging shape during the shear test. Both specimens formed shear planes at failure. As previously mentioned, Method V-I for the hydrostatic test and Method S-1 for the shear test will be considered as the standard analysis methods for purposes of comparison.

\subsection{COMPARISON FOR HYDROSTATIC TESTS}

Pressure-volumetric strain plots for the sandy clay specimen during the hydrostatic loading test are shown in Figure 4.1 for each of the six methods previously described for calculation of volumetric strain. Values of volumetric strain and approximate bulk moduli $K$, calculated for both the 0- to 100-psi and the 600- to 1,000-psi pressure ranges, are also included in Figure 4.1. Method V-2 yielded 
essentially the same strain values as the standard Method V-1, because of the equality of the two methods except in small-order terms. Method V-4 resulted in only slightly greater volumetric strain; i.e. the difference between this method and the standard is unnoticeable on the plots for volumetric strains less than 5 percent, which is reasonable to expect since the dead zone considered in the calculation was very small compared to the large original volume. Methods V-6, $\mathrm{V}-3$, and $\mathrm{V}-5$ gave substantially larger strains than did the standard method. At lower pressures (less than $100 \mathrm{psi}$ ), these three methods are in close agreement with strains exceeding the standard by approximately 50 percent. At higher pressures, i.e. 1,000 psi, Method V-5 gave the largest strain, exceeding the standard by approximately 65 percent. Methods V-6 and V-3 showed fairly close agreement, exceeding the standard strain at 1,000 psi by about 45 percent. It should be noted that since the deformation results are material-response dependent, the same percentage difference may not hold for different materials. In fact, similar calculations by WES using other test data resulted in Method V- 6 giving the largest volumetric strain values; however, Methods V-1, V-2, and V-4 will probably always give smaller volumetric strains than Methods $\mathrm{V}-3, \mathrm{~V}-5$, and $\mathrm{V}-6$.

Comparison of bulk moduli values for the pressure range of 0 to 100 psi shows that the maximum bulk modulus was calculated from Method $\mathrm{V}-1$. The lowest modulus, calculated from Method V-6, was 35 percent less than the standard. Values of bulk moduli for the high pressure range, 600 to 1,000 psi, varied from 57 percent less than to 21 percent greater than the standard. The lowest modulus was calculated by Method V-5 and the greatest modulus by Method V-6. Again because of the dependence of the deformations on material-response behavior, there are no fixed relations between methods.

The same basic trends observed for the relatively soft sandy 
clay specimen are apparent in the pressure-volumetric strain plots for the relatively stiff siltstone specimen as shown in Figure 4.2. Methods V-1, V-2, and V-4 gave essentially the same volumetric strain results. Again Methods $\mathrm{V}-3, \mathrm{~V}-5$, and $\mathrm{V}-6$ gave substantially larger strains ranging from 40 percent (Method V-6) to 63 percent (Method $\mathrm{V}$-5) greater than the standard at a pressure of 1,500 psi. At a pressure of 200 psi, the volumetric strain calculated by Method V-5 was 110 percent greater than that calculated by the standard method. Note also that, while Method V-6 gave larger strains at high pressure, it gave lower strain values than the standard method in the low pressure range.

The bulk moduli values varied from a low of 42 percent less than that calculated from the standard at low pressures (200 to $600 \mathrm{psi}$ ) to 45 percent less than the standard at high pressures (1,200 to 1,500 psi). Method V-5 gave the lowest modulus for the low pressure range while Method V-6 gave the lowest value for the high pressure range. At the low pressure range, the bulk modulus as calculated from Method V-6 compared favorably with the standard.

From the two above examples, several rather general observations can be made regarding the comparison of methods to calculate volumetric strain. First, the results indicate that the volumetric strains are different at any given pressure when calculated by Methods $\mathrm{V}-5$ and $\mathrm{V}-6$. Both methods are based on the theory of elasticity, which assumes for hydrostatic compression that axial and radial strains are equal; one method used only axial strains and the other only radial strains to calculate volumetric strains. Obviously the axial and radial strains as derived from the axial and radial deformations of the specimens were not equal nor were the specimens elastic.

Far from being elastic solids, soil specimens are in fact 
multiphase mixtures of air, water, and mineral particles. Thus, under hydrostatic loading, overall specimen compressibility is governed primarily by the compressibility of the air as it is driven into solution. After full saturation has been achieved, specimen compressibility is then governed only by the compressibility of the water and solids, which should result in noticeable stiffening in pressure versus volumetric strain behavior. The volumetric strain at which this stiffening occurs should correspond approximately to the initial percentage of air contained within the specimen. The initial volume percentage of air contained in the sandy clay was calculated to be 12.7 percent as shown in Figure 2.3; the hydrostatic pressure versus volumetric strain plot for Method V-5 (Figure 4.1) shows a noticeable stiffening at a volumetric strain of approximately 13 percent. The initial volume percentage of air for the siltstone specimen is 2.8 percent as shown in Figure 2.4; although the hydrostatic loading for this test was not carried to a sufficiently high pressure to verify complete saturation, Method V-5 again appears to indicate stiffening at the appropriate strain, i.e. around 2.8 to 2.9 percent. The above observations, based on air voids calculated for two test specimens, by no means offer conclusive evidence as to the validity of Method V-5; but they do illustrate the value of material-composition information in the interpretation of mechanical-property test data.

There is a general trend of the methods to combine into two groups: one group, consisting of Methods V-1, V-2, and V-4, tends to give low strain values; and the other group, consisting of Methods V-3, V-5, and $V-6$, tends to give high strain values. A possible bounding of the volumetric strain response of soil under hydrostatic loading may result from the use of the standard Method $V-I$ (as a lower bound) and Method V-3 (as an upper bound).

Finally, without additional information regarding the stress and 
strain distribution within each specific triaxial specimen, there appears to be no reason why the standard Method V-I, based on actual measurements, should not continue to be used to develop plots for data presentation, but the results from this method should not be used in constitutive property analyses without due consideration of the possible errors involved.

\subsection{COMPARISON FOR SHEAR TESTS}

Deviator stress versus deviator strain plots for the sandy clay specimen during the shear phase of the test are shown in Figure 4.3 for each of the six methods previously described for calculation of deviator stress and strain. A table listing the deviator strains and approximate shear moduli for two deviator stress ranges is included in the same figure; Method S-l will be considered the standard for comparison purposes. Note first the similarity between all the curves and the relatively tight data band produced by Methods $\mathrm{s}-1, \mathrm{~s}-2, \mathrm{~s}-3$, and $\mathrm{S}-4$. Considering the deviator stress at a deviator strain of 4 percent as an indication of ultimate yield strength, the results for all six methods only ranged from a high of 8 percent greater (Method $\mathrm{S}-5$ ) to a low of 7 percent less (Method S-6) than that given by the standard method. The shear moduli values calculated for the higher deviator stress range (100 to $150 \mathrm{psi}$ ) tend to show more scatter, however. The maximum shear modulus in this pressure range as calculated by Method S-5 was 29 percent greater than the standard of 2,300 psi and the lowest shear modulus by Method S-6 was 35 percent less than the standard.

The variation in initial shear moduli data can best be seen in Figure 4.4, which is an enlarged view of the initial portion of the deviator stress-strain curves presented in Figure 4.3. Although there is a more noticeable deviation from the standard by Methods $\mathrm{S}-5$ and 
S-6, the tight banding of Methods $\mathrm{S}-1, \mathrm{~s}-2, \mathrm{~S}-3$, and $\mathrm{S}-4$ is still evident. The range of shear moduli for the 0 - to 70-psi pressure range varied from a high of 115 percent greater than the standard for Method S-5 to a low of 48 percent less than the standard for Method S-6. The deviator stresses compared at 1 percent deviator strain ranged from 16 percent greater than the standard to a low of 19 percent less than the standard value.

The deviator stress-deviator strain plot for the shear phase of the siltstone test is shown in Figure 4.5. Although the curves tend to produce the same general trend, the values as calculated by Methods $\mathrm{S}-1, \mathrm{~S}-2, \mathrm{~S}-3$, and $\mathrm{S}-4$ are not as close as in the sandy clay example. The deviator stress values taken at 0.6 percent deviator strain as an indication of ultimate yield strength range from a high of 23 percent greater to a low of 21 percent less than the comparable deviator stress value from the standard method. The yield strength is not shown in Figure 4.5, but based on calculations for the complete shear test data, the maximum yield strength is approximately the same value for all methods although the corresponding deviator strain values range from 40 percent less than to 100 percent greater than the deviator strain value of 1.5 percent calculated at maximum deviator stress by the standard method. The shear moduli values taken at high deviator stress levels (400 to 600 psi) vary from a high of 51 percent greater than the standard for Method S-5 to a low of 33 percent less than the standard for Method S-6. The shear moduli values taken at the medium deviator stress range (200 to $400 \mathrm{psi}$ ) vary from 42 percent greater than to 38 percent less than the values calculated by the standard method.

An expanded view of the initial portion of the deviator stressdeviator strain plot for the siltstone test is shown in Figure 4.6. The curves for this particular test, however, were based primarily 
on extrapolation of data measured at higher stress levels; and, although other test data have shown that the various calculation methods do affect the initial portion of the shear results, use of these particular data will only demonstrate possible variations. The standard method gives the minimum numerical value of deviator strain for any given deviator stress level, while Method s-6 still gives the maximum numerical value of deviator strain. Method'S-5 yields the second highest value of deviator strain up to approximately 200-psi deviator stress. Methods $\mathrm{S}-2$ and $\mathrm{S}-3$ give similar results. The shear moduli values in the 0- to 100-psi stress range decrease in value from the standard of 555,000 psi to a minimum of 167,000 psi as calculated by Method S-6.

Several observations can be made based on the calculated stressstrain results shown for the two shear test examples. In general, all the calculation methods will give approximately the same values for maximum yield strength, but significantly different values for the deviator strain at which maximum yield strength occurs. Methods S-1, S-2, S-3, and S-4 appear to give approximately the same overall stress-strain results with their curves bounded from above by the stress-strain curve calculated by Method S-5 and from below by the curve calculated by Method S-6. Bounding for the initial shear modulus does not appear feasible as yet since, at low deviator stress values, any of the methods could yield the maximum shear modulus except Method S-6, which appears to give the lowest values of shear modulus regardless of material type. Method S-6, however, was based on an arbitrary correction of axial deformation and the results with this method therefore can only be considered as an illustration. Basically the standard method, $S-I$, is considered satisfactory at this time for the calculation of deviator stress and deviator strain from laboratory load and deformation measurements since it 
does tend to produce an average of the stress-strain results as calculated from the other five methods.

Although triaxial test results are seldom, if ever, presented in terms of deviator stress versus volumetric strain, comparison of such plots based on the various stress and strain calculation methods previously described may be beneficial in view of recent interest by developers of constitutive models in the volume change characteristics of soils and rocks during shear. Results for the siltstone example test are presented in Figure 4.7. It is realized that there is some question regarding the proper usage of Methods V-5 and V- 6 to calculate volumetric strain during the shear phase of the test; however, the calculated results do illustrate trends. The values of deviator stress were calculated for all six volumetric strain calculation cases by Method S-I; volumetric strains were not rezeroed at the start of the shear phase, but were continued from the last point which occurred during the hydrostatic phase.

Methods $\mathrm{V}-1, \mathrm{~V}-2$, and $\mathrm{V}-4$ show initial volume increase followed by a volume decrease to failure. Method V-3 shows an initial volume increase followed by little change in volumetric strain to peak deviator.stress. Method V-5 shows little initial volume change followed by an increasing rate of decreasing volume. Method V- 6 shows a relatively constant rate of increasing volume change followed by a rapid increase near peak stress.

The principal observation that can be made based on the results shown in this example is that any conclusions made from triaxial test results as to whether dilation, compaction, or no volume change occurs or does not occur during shear of a given material may be completely masked by the particular method of data analysis chosen by the experimenter. 


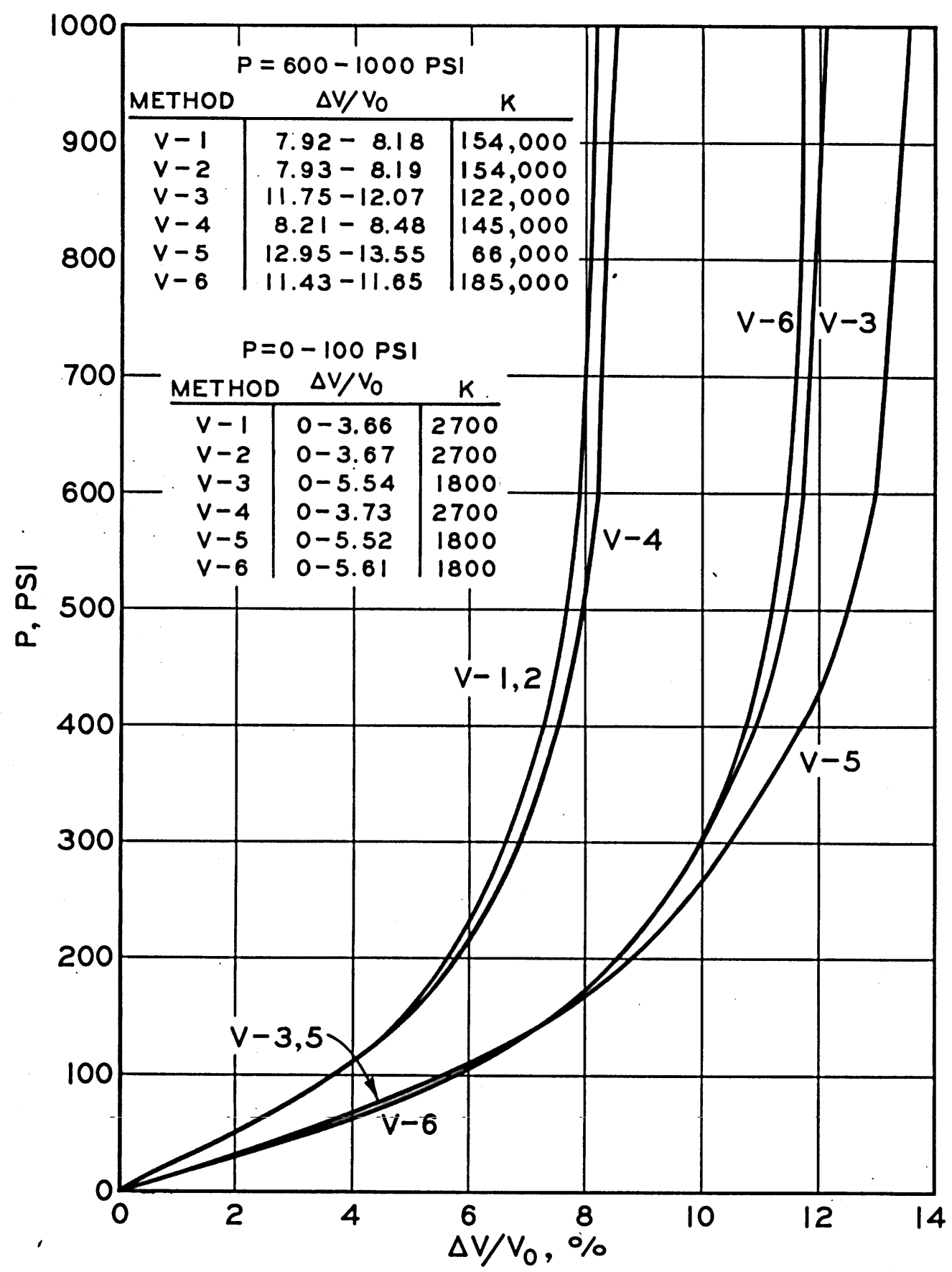

Figure 4.1 Comparison of methods used to calculate volumetric strain for the sandy clay test. 


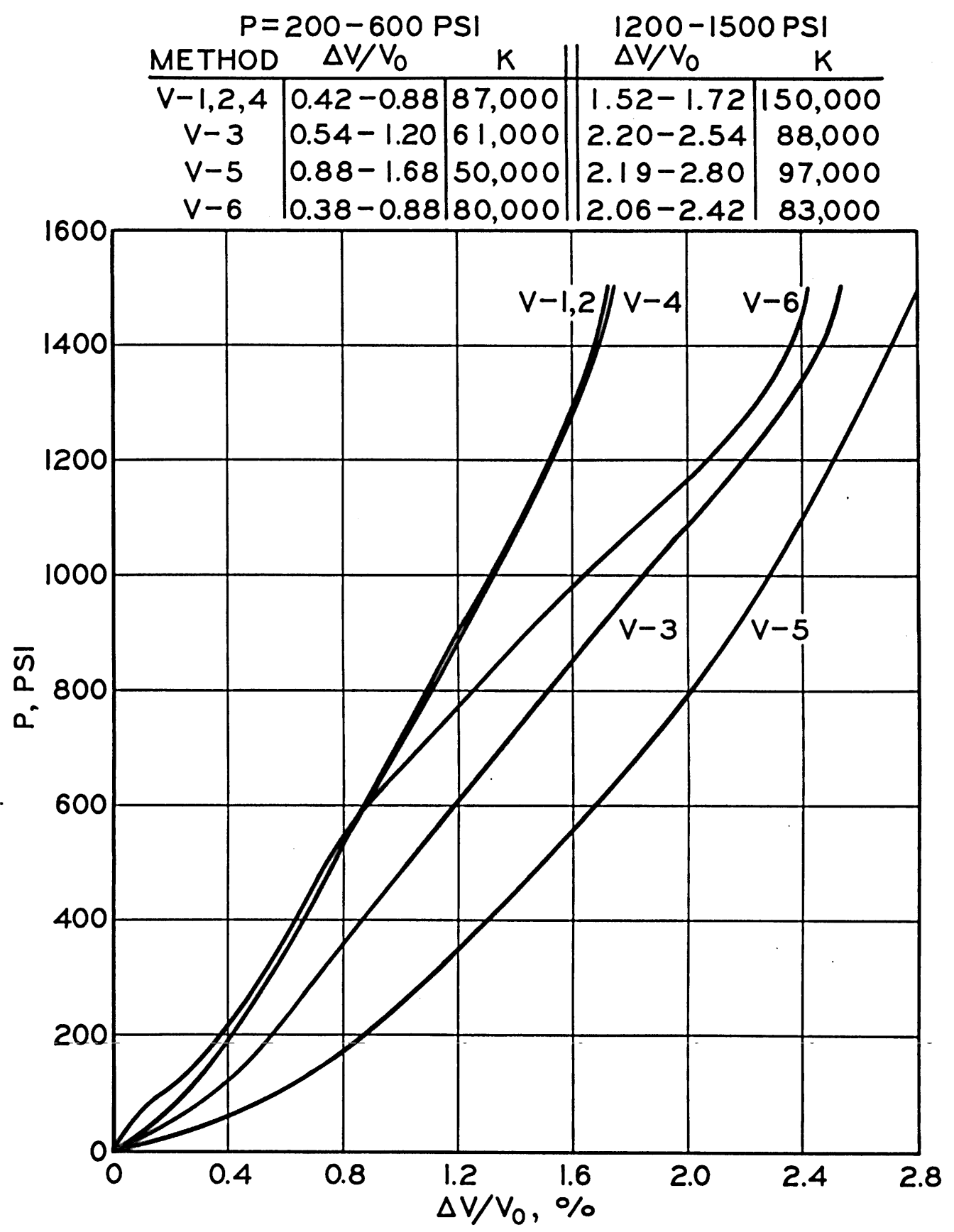

Figure 4.2 Comparison of methods used to calculate volumetric strain for the siltstone test. 


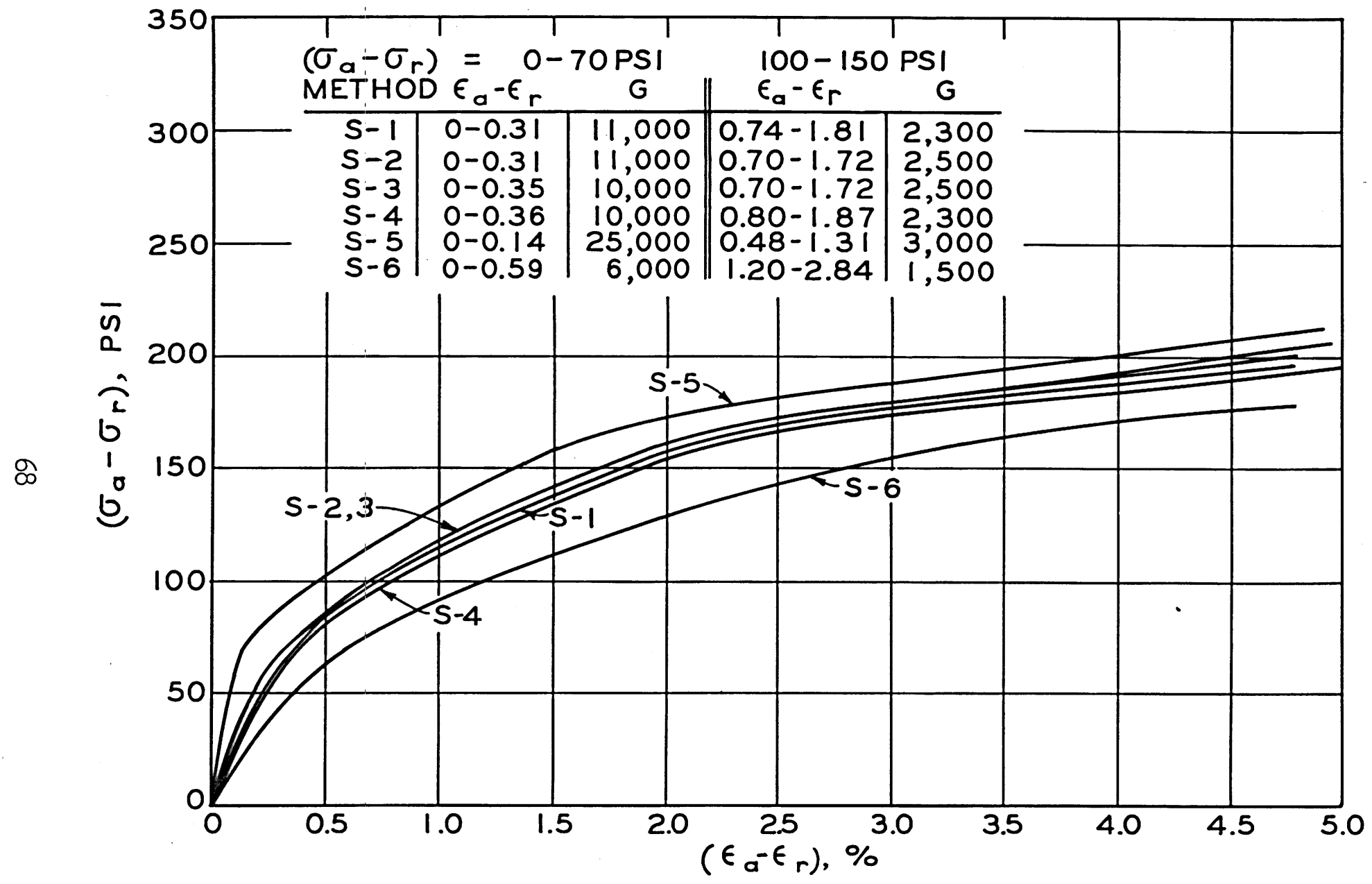

Figure 4.3 Comparison of methods used to calculate deviator stress and deviator strain for the sandy clay test. 


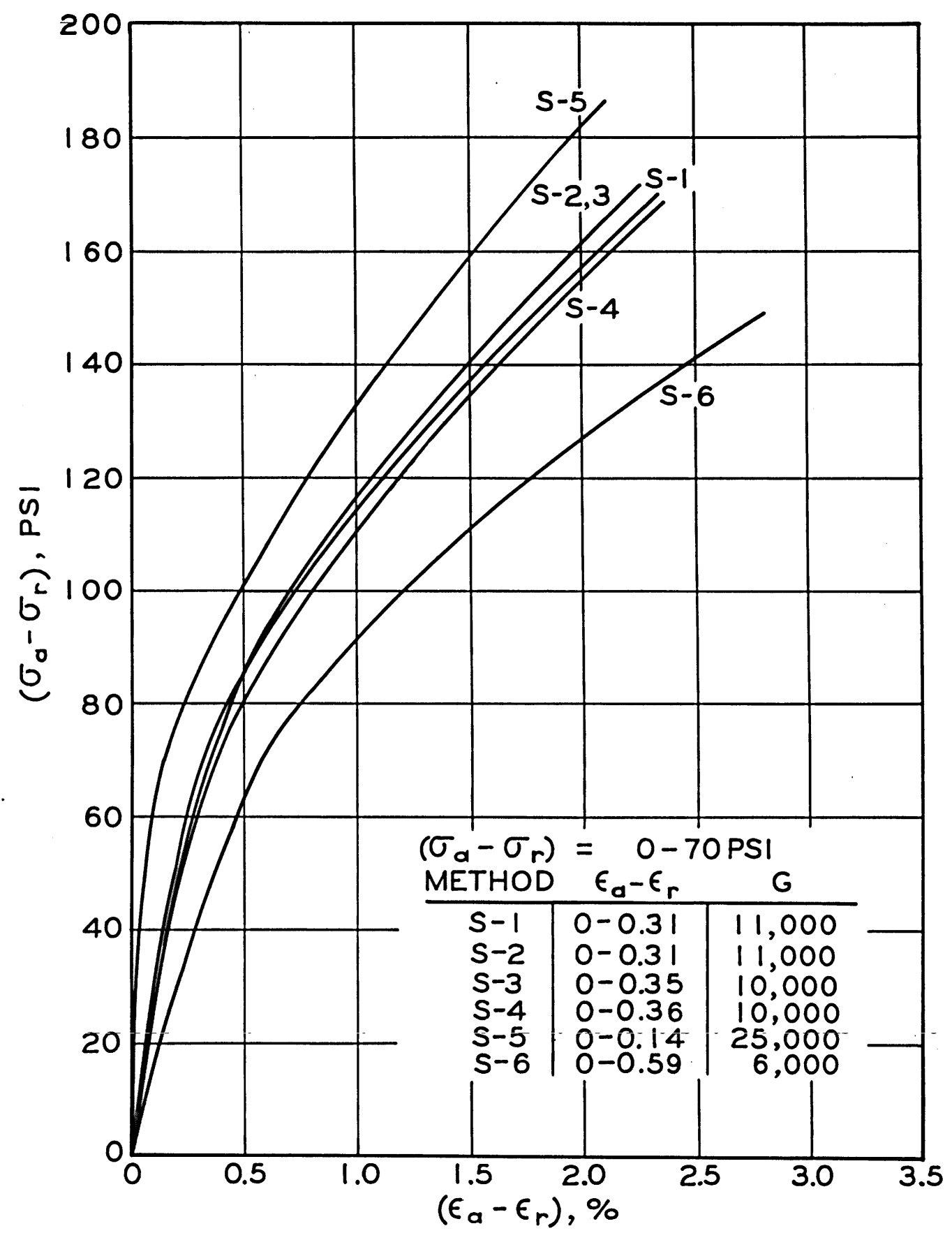

Figure 4.4 Initial portion of plots shown in Figure 4.3. 


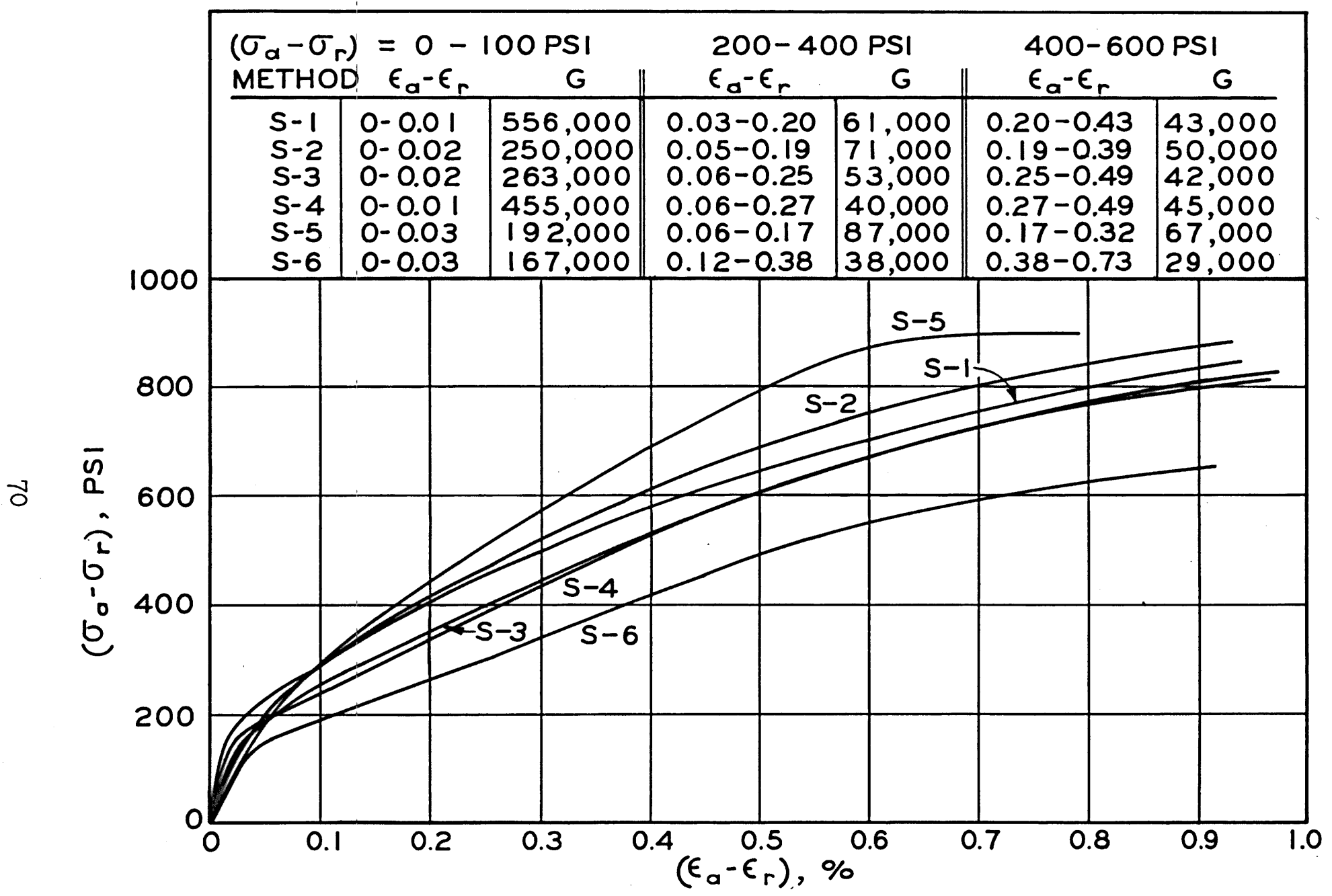

Figure 4.5 Comparison of methods used to calculate deviator stress and deviator strain for the siltstone test. 


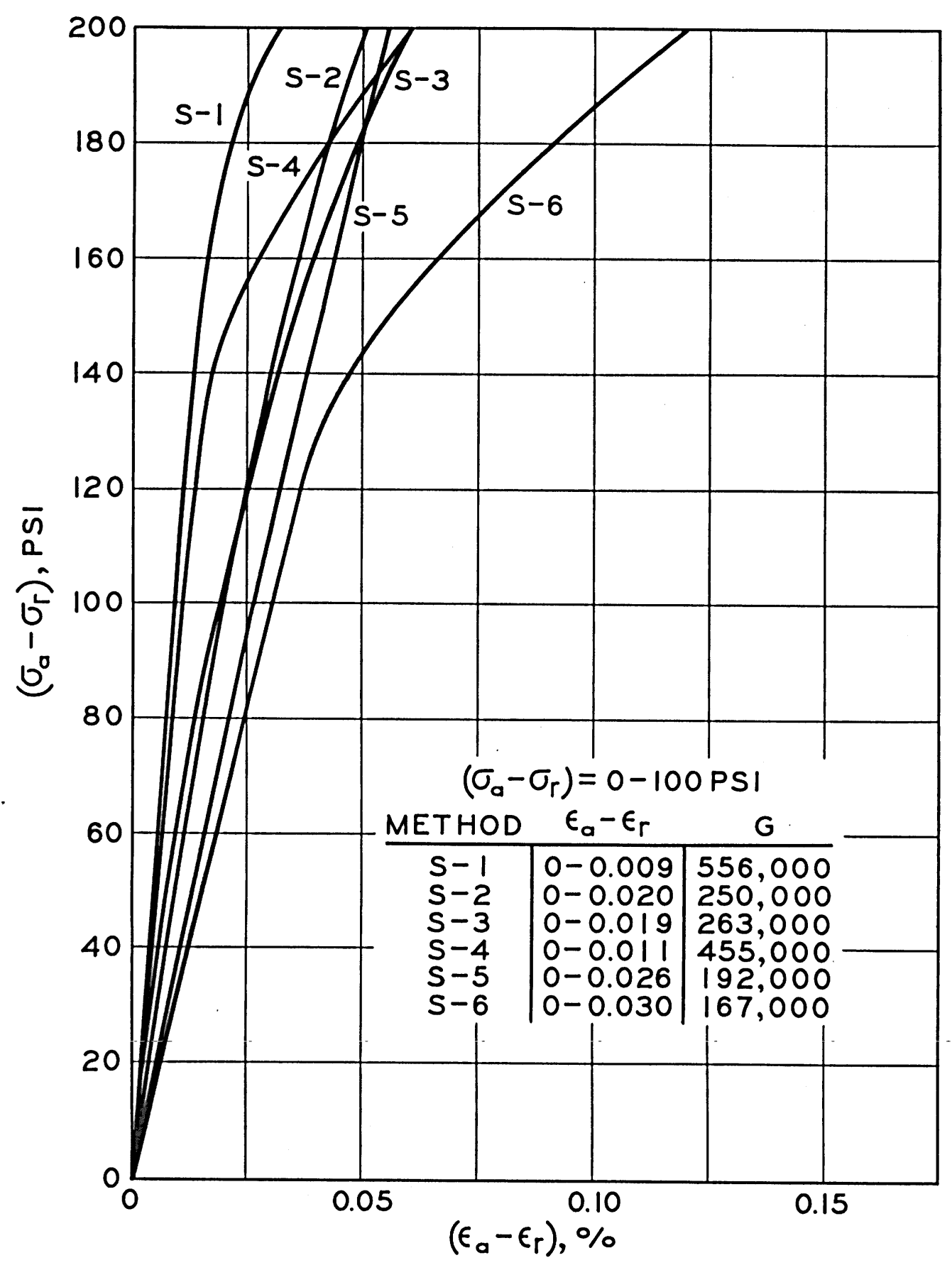

Figure 4.6 Initial portion of plots shown in Figure 4.5 (based on extrapolation of test data). 


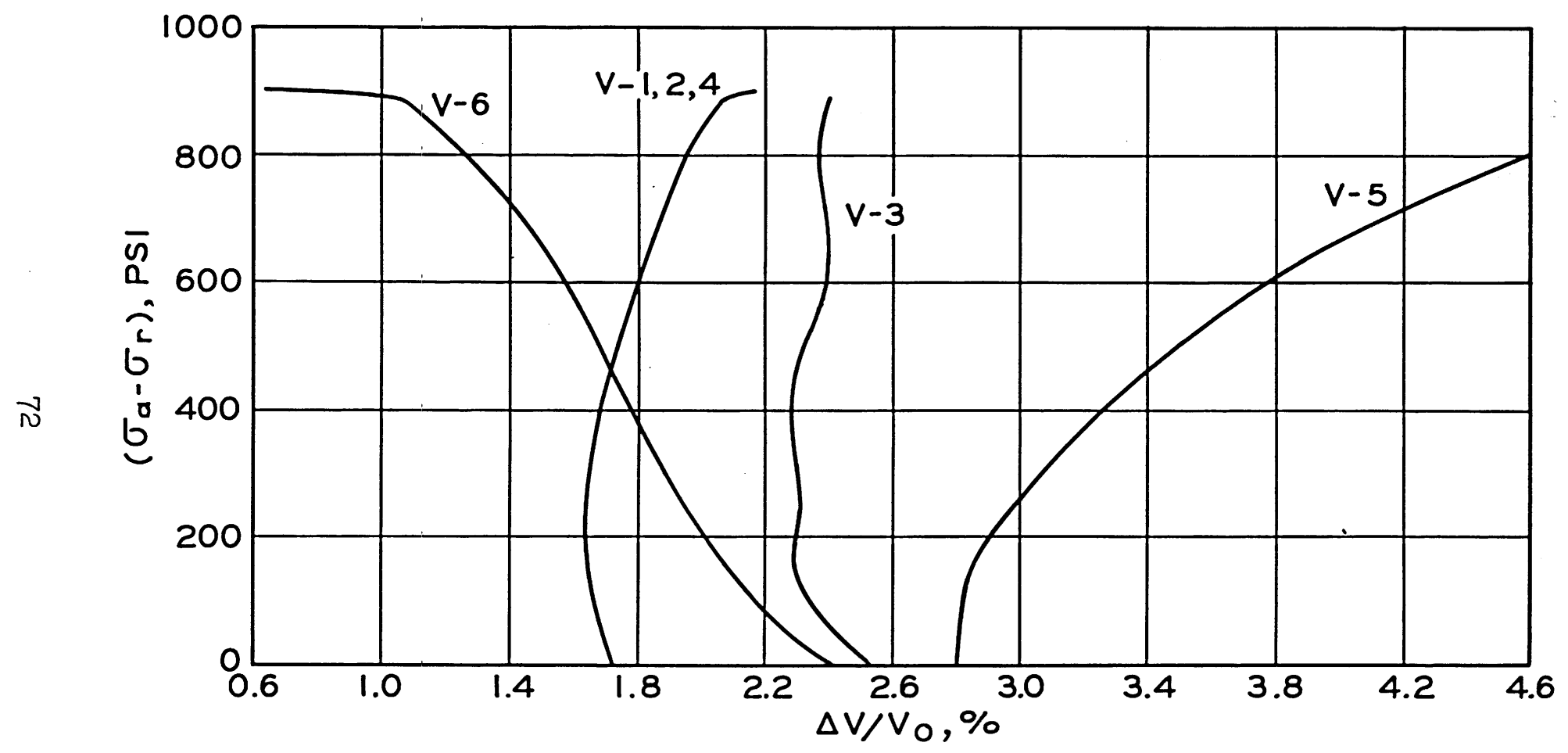

Figure 4.7 Comparison of methods used to calculate volumetric strain during shear for the siltstone test. 
CHAPTER 5

CONCLUSION

The purpose of this paper was to show with specific examples the possible influence exerted due to interpretation of raw load and deformation data on the stress-strain relations obtained from laboratory tests. The triaxial test was selected for illustration purposes, and observations were made regarding physical response of typical specimens subjected to both hydrostatic loading and shear loading. Six methods to calculate volumetric strain and deviator stress and strain were derived based on a variety of empirical and theoretical approaches and applied to calculate stress-strain relations for two widely different materials.

Results of the hydrostatic phase calculations indicated that volumetric strains were generally bound by Methods V-l (lowest values) and V-3 (highest values); the actual hydrostatic stress-volumetric strain response of a given soil or rock material probably lies within those bounds. Results from the shear phase calculations indicated that the use of Method S-I to calculate the overall deviator stressdeviator strain curve is probably satisfactory; however, selection of an initial value for shear modulus must depend to a great degree on the compatibility with moduli observed from tests conducted under other states of stress.

Research is under way to develop improved measurement systems which attempt to circumvent the important inf'Iuence of imposed boundary condition on the specimen's stress-strain behavior. Finite element analyses of laboratory tests are also under way to provide some insight into the degree of influence of boundary conditions on the distribution of stress and strain within the specimen and possibly to disclose procedures for relating externally measured loads and 
deformations to the most representative stress-strain behavior of a given test specimen. Until the results of such research are available, continued use of the standard methods, i.e. Method V-l for volumetric strain and Method S-I for deviator stress and strain, to develop plates for triaxial test data presentation appears justified.

Code developers can provide very useful information to experimenters through their ability to conduct controlled parameter studies of the influence of material properties in ground shock calculation; results from such studies can enable the experimenter to concentrate his research efforts on those properties having the greatest influence on wave propagation through earth materials. There are certain favorite areas that experimenters like to investigate which may or may not have any influence on the propagation of ground shock while other overlooked areas might be of prime importance.

Hopefully, through a coordinated research effort, such as the DASA-sponsored program at WES, significant results will be attained for use not only in the specific area of constitutive model formulation for ground shock codes, but also for broad application in the general field of soil and rock mechanics. 


\section{REFERENCES}

1. G. F. Sowers; "Strength Testing of Soils, Laboratory Shear Testing of Soils"; ASTM Special Technical Publication No. 361, 1964, Pages 3-5, 9-14; Unclassified.

2. A. W. Bishop and D. V. Henkel; "The Measurement of Soil Properties in the Triaxial Test"; Second Edition, 1962; Edward Arnold, London; Unclassified.

3. W. G. Shockley and R. G. Ahlvin; "Non-Uniform Conditions in Triaxial Test Specimens"; Research Conference on Shear Strength of Cohesive Soils, 1960, Page 341; American Society of Civil Engineers, Boulder, Colorado; Unclassified.

4. "Strain Variation in a Triaxial Soil Test"; Technical Documentary Report No. AFWL TDR-64-47, September 1964, Pages 17-18; IIT Research Institute for U. S. Air Force Weapons Laboratory, Research and Technology Division, Contract AF 29(601)-6004; Unclassified.

5. B. B. Mazanti and C. N. Holland; "Study of Soil Behavior Under High Pressure"; Contract Report S-70-2, Report 1, Vol. 1, February 1970; U. S. Army Engineer Waterways Experiment Station, CE, Vicksburg, Miss.; Unclassified.

6. J. M. Duncan and P. Dunlop; "The Significance of Cap and Base Restraint"; Journal of the Soil Mechanics and Foundations Division, January 1968, Vol. 94, No. SMl, Pages 271-289; American Society of Civil Engineers; Unclassified.

7. P. W. Rowe and L. Barden; "Importance of Free Ends in Triaxial Testing"; Journal of the Soil Mechanics and Foundations Division, January 1964, Vol. 90, SMl, Proc Paper No. 3753, Pages 1-27; American Society of Civil Engineers; Unclassified. 
DISTRIBUTION LIST FOR MISCELIANEOUS PAPER S-71-9

Address

No. of

Copies

\section{Army}

Chief of Engineers, Department of the Army

ATTN: ENGMC-ED

ENGAS-I

1

1

Washington, D. C. 20314

Division Engineer

U. S. Army Engineer Division, Huntsville

ATTN: Mr. T. R. Wathen

1

Mr. M. M. Dembo

1

P. 0. Box 1600, West Station

Huntsville, Ala. 35807

District Engineer, U. S. Army Engineer District, Omaha

6012 U. S. Post Office and Court House

215 North 17th Street

Omaha, Nebr. 68101

Director of Civil Defense, Office of the Secretary of the Army 1 ATTN: Engineering Development Division (Research Directorate) Washington, D. C. 20310

Chief of Research and Development, Department of the Army

ATTN: Atomic Office CRDES

Washington, D. C. 20310

1

Chief of Research and Development, Headquarters,

Department of the Army

ATTN: Director of Army Technical Information

3 copies

of Form

Washington, D. C. 20310

1473

Director, Nuclear Cratering Group

1

U. S. Army Corps of Engineers

Lawrence Radiation Laboratory

P. 0. Box 808

Livermore, Calif. 94550 


\section{Army (Continued)}

Commanding Officer, U. S. Army Nuclear Defense Laboratory ATTN: Technical Library

Edgewood Arsenal

Edgewood, Ma. 21040

Director, U. S. Army Cold Regions Research and

Engineering Laboratory

ATTN: Mr. K. Boyd

P. O. Box 282

Hanover, N. H. 03755

\section{$\underline{\text { Navy }}$}

Commander, Naval Facilities Engineering Command, Navy Department

ATTN: Code 04

Code 03

Washington, D. C. 20370

1

1

Chief of Naval Research, Navy Department

ATTN: Code 811

Washington, D. C. 20390

Commanding Officer \& Director

U. S. Naval Civil Engineering Laboratory

ATTN: Library

Mr. C. R. White

$\mathrm{Mr}$. H. L. Gill

Port Hueneme, Calif. 93041

Air Force

Air Force Weapons Laboratory

ATTN: Library

WLDC

Dr. H. F. Cooper, Jr.

CPT H. E. Selheimer

Kirtland AFB, N. Mex. 87117
1

1

1

1 
Space and Missile Systems Organization

ATTN : SMQHE

SMQHF- 1

Norton AFB, Calif. 92409

Director of Civil Engineering

Headquarters, USAF

ATTN: AFOCE

Washington, D. C. 20330

Director, U. S. Air Force Project RAND

Via: U. S. Air Force Liaison Office

The Rand Corporation

1700 Main Street

ATTN: Library

Santa Monica, Calif. 90406

\section{Colleges and Universities}

Brown University

Division of Engineering

ATTIN: Dr. W. Prager

Providence, R. I. 02912

George Washington University

Department of Engineering Mechanics

ATTN: Dr. A. Freudenthal

Washington, D. C. 20006

University of California

Lawrence Radiation Laboratory

P. 0. Box 808

ATTN: Technical Information Division

Livermore, Calif. 94550 
Colleges and Universities (Continued)

The Citadel

COL Himelright

Civil Engineering Department

Charleston, S. C. 29409

City College of New York

Department of Civil Engineering

ATTN: Dr. C. J. Costantino

New York, N. Y. 10010

Columbia University

Professor Robert D. Stoll

638 seeley W. Mudd Building

New York, N. Y. 10027

Duke University

Department of Civil Engineering

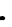

ATTN: Professor Aleksander B. Vesic

Durham, N. C. 27706

University of Florida

Civil Engineering Department

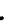

ATTN: Professor J.H. Schmertmann

Gainesville, Fla. 32601

Georgia Institute of Technology

School of Civil Engineering

ATTN: Dr. B. B. Mazanti

Atlanta, Ga. 30332

Howard University

Department of Civil Engineering

ATTN: Dr. Delon Hampton

Washington, D. C. 20001 


\section{Colleges and Universities (Continued)}

University of Illinois, Department of Civil Engineering

ATTN: Professor A. J. Hendron, Jr.

1

Professor N. M. Newmark

1

Professor R. B. Peck

Urbana Campus

Urbana, IIl. 61801

University of Kentucky, Department of Civil Engineering

ATTN: Professor B. O. Hardin

Lexington, Ky. 40506

Louisiana State University, Department of Civil Engineering 1 ATTN: Dr. J. K. Poplin

Baton Rouge, La. 70803

University of Michigan, Department of Civil Engineering . I ATTN: Professor F. E. Richart, Jr.

Ann Arbor, Mich. 48104

University of New Mexico, Civil Engineering Research Facility

ATTN: Mr. Delmar E. Calhoun

Dr. G. Triandafilidis

P. 0. Box 188

1

1

University Station

Albuquerque, N. Mex. 87106

State University of New York, Department of Civil Engineering I ATTN : Dr. Ernest T. Selig

Buffalo, N. Y. 14214

North Carolina State University

ATTN: Professor Ralph E. Fadum

Box -5628

Raleigh, N. C. 27607 


\section{Colleges and Universities (Continued)}

Northwestern University, Department of Civil Engineering ATTN: Associate Professor Raymond J. Krizek Technological Institute Evanston, III. 60201

Purdue University, School of Civil Engineering ATTN: Professor Gerald A. Leonards Lafayette, Ind. 47907

University of Texas, Civil Engineering Department ATTN: Professor H. Neils Thompson Austin, Tex. 78712

University of Utah ATTN: Dr. Wayne Brown Department of Mechanical Engineering

Salt Lake City, Utah 84112

Massachusetts Institute of Technology, Division of Sponsored Research

ATTN: Dr. Robert V. Whitman

77 Massachusetts Avenue

Cambridge, Mass. 02139

California Institute of Technology, Division of Engineering ATTN: Dr. Ronald Scott Pasadena, Calif. 91109

University of California ATTN: Professor H. Bolton Seed

Room 301, Engineering Materials Laboratory. Berkeley, Calif. 94720

Texas A\&M University, Department of Civil Engineering ATTN: Professor L. J. Thompson Professor W. A. Dunlap Professor J. Hardin

College Station, Tex. 77843 
Professor Arthur Casagrande

16 Rockmont Road

Blemont, Mass. 02178

D'Appolonia Consulting Engineer

ATTN: Dr. John R. Hall, Jr.

15 Duff Road

Pittsburgh, Pa. 15235

Director, Advanced Research Projects Agency

ATTN: Dr. Stanley Ruby (NMRO-RM. 3D170)

The Pentagon

Washington, D. C. 20315

Aerospace Corporation

ATTN: Dr. S. B. Batdorf

Dr. M. B. Watson

1111 E. Mill Street

San Bernardino, Calif. 92408

Agbabian-Jacobsen Associates, Engineering Consultants

1

8939 South Sepulveda Boulevard

Los Angeles, Calif. 90045

Applied Theory Incorporated

ATTN: Dr. John G. Trulio

Mr. W. J. Niles

1

1

1010 Westwood Boulevard

Los Angeles, California 90024

Battelle Memorial Institute

ATTN: Mr. R. W. Klingesmith

Dr. P. N. Lamari

$505^{-K i n g}$ Avenue

Columbus, Ohio 43201

The Boeing Company, Aerospace Group

Missile and Information Systems Division

ATTN: Mr. H. G. Leistner

$\mathrm{Mr}$. Joel K. Bloomer

P. 0. Box 3985

Seattle, Wash. 98124 
ATTN: SPSS

Washington, D. C. 20301

Defense Documentation Center (DDC)

ATTN: Mr. Myer Kahn

Cameron Station

Alexandria, Va. 22314

(NO TOP SECRET TO THIS ADDRESS)

Director of Defense Research and Engineering

ATrN: Technical Library

Washington, D. C. 20301

Defence Research Establishment, Suffield

Ralston, Alberta, Canada

Denver Mining Research Center

ATTN: Dr. Leonard A. Obert

Building 20, Denver Federal Center

Denver, Colo. 80225

General Electric Company, TEMPO

ATTN: . Mr. Warren Chan (DASIAC)

816 State Street

Santa Barbara, Calif. 93101

General Motors Corporation, Manufacturing Development

ATTN: Mr. W. M. Isbell

Technical Center

Warren, Mich. 48090

IIT Research Institute

ATTN: Library

Dr. E. Vey

1

10 West 35th Streer

Chicago, Ill. 60616 
Mrr. W. R. Perret

jil2 Sandia Laboratories

Sandia Base

Albuquerque, N. Mex. 87115

Systems, Science \& Software

A'TTN: $\mathrm{Mr}$. Robert T. Allen

P. 0. Box 1620

La Jolla, Calif. 92037

Physics International Company

ATTN: Dr. Charles Godfrey

1

Mr. Fred M. Sauer

2700 Merced Street

San Leandro, Calif. 94577

TRW Systems

ATTN: Dr. Peter Dai

1

Mr. Norman Lipner

1

One Space Park

Redondo Beach, Calif. 90278

TRW Systems

ATTN: Mr. Fred A. Pieper

P. 0. Box 1310

San Bernardino, Calif. 92402

Paul Weidlinger, Consulting Engineer

ATTN: Dr. M. L. Baron

Dr. Ivan Nelson

110 East 59th Street

New York, N. Y. 10022

Mr. G. F. Weissmann

Room 1B-124, Bell Telephone Laboratories

Murray Hill, N. J. 07971

Shannon and Wilson, Incorporated

ATTN: Mr. Earl A. Sibley

1105 North 38th Street

Seattle, Wash. 98103 
Unclassified

Security Classification

\section{DOCUMENT CONTROL DATA - R \& D}

(Security classillication of title, body of abstract and indexing annotation must be entored whon the overall report le claselfled)

U. S. Army Engineer Waterways Experiment Station Vicksburg, Miss.

20. REPORT SECURITY CLASSIFICATION Unclassified

2b. GROUP

3. REPORT TITLE

CALCULATION OF STRESS AND STRAIN FROM TRIAXIAL TEST DATA ON UNDRAINED SOIL SPECIMENS

4. DESCRIPTIVE NOTES (TYPO of roport and Inclualve dates)

Final report

B. AUTHOR(S) (FIrat name, middlo initial, la tet namo)

John Q. Ehrgott

\begin{tabular}{|c|c|c|}
\hline $\begin{array}{l}\text { O. REPOAT DATE } \\
\text { MaY } 1971\end{array}$ & & \begin{tabular}{|c|c|} 
7a. TOTAL NO. OF PAGES & 7b. NO. OF REFS \\
83 & 7 \\
\end{tabular} \\
\hline $\begin{array}{l}\text { O. CONTRACT OR GRANT NO. } \\
\text { b. PROJE'CT NO. }\end{array}$ & . & $\begin{array}{l}\text { 9a. ORIGINATOR'S REPORT NUMBER(S) } \\
\text { Miscellaneous Paper S-71-9 }\end{array}$ \\
\hline c. & • & $\begin{array}{l}\text { 9b. OTHER REPORT NO(S) (Any other numbere that may be aeelened } \\
\text { ihie roport) }\end{array}$ \\
\hline
\end{tabular}

Approved for public release; distribution unlimited.

11. SUPPLEMENTAAY NOTES Paper presented at Eric 12. SPONSORING MILITARY ACTIVITY

C. Wang Symposium on Protective Structures

Technology, Air Force Weapons Laboratory,

Kirtland AFB, N. Mex., 21-23 July 1970.

Defense Atomic Support Agency

Washington, D. C.

13. ABSTAACT The formulation of constitutive relations for use in computerized analyses

of free-field ground shock phenomena is based primarily on laboratory-determined

material properties. These properties, as described by stress-strain relations, are

not directly determined in the laboratory, but are derived through interpretation of

load and deformation data measured by the experimenter. Throughout this paper, one

laboratory test, the triaxial shear test, is used to illustrate the extent of inter-

pretation required on raw data and the influence of this interpretation on recommended

constitutive properties. Various techniques that have been developed to obtain

stress-strain data from the triaxial test are reviewed along with current advances in

measurement systems. Typical raw data are presented and calculations of axial,

lateral, and volumetric strains are made based on a variety of empirical and theoret-

ical approaches. The results demonstrate that research and development efforts are

still required in the area of material property testing in order to establish adequate

confidence in the formulation of constitutive relations for ground shock calculations. 
Unclassified

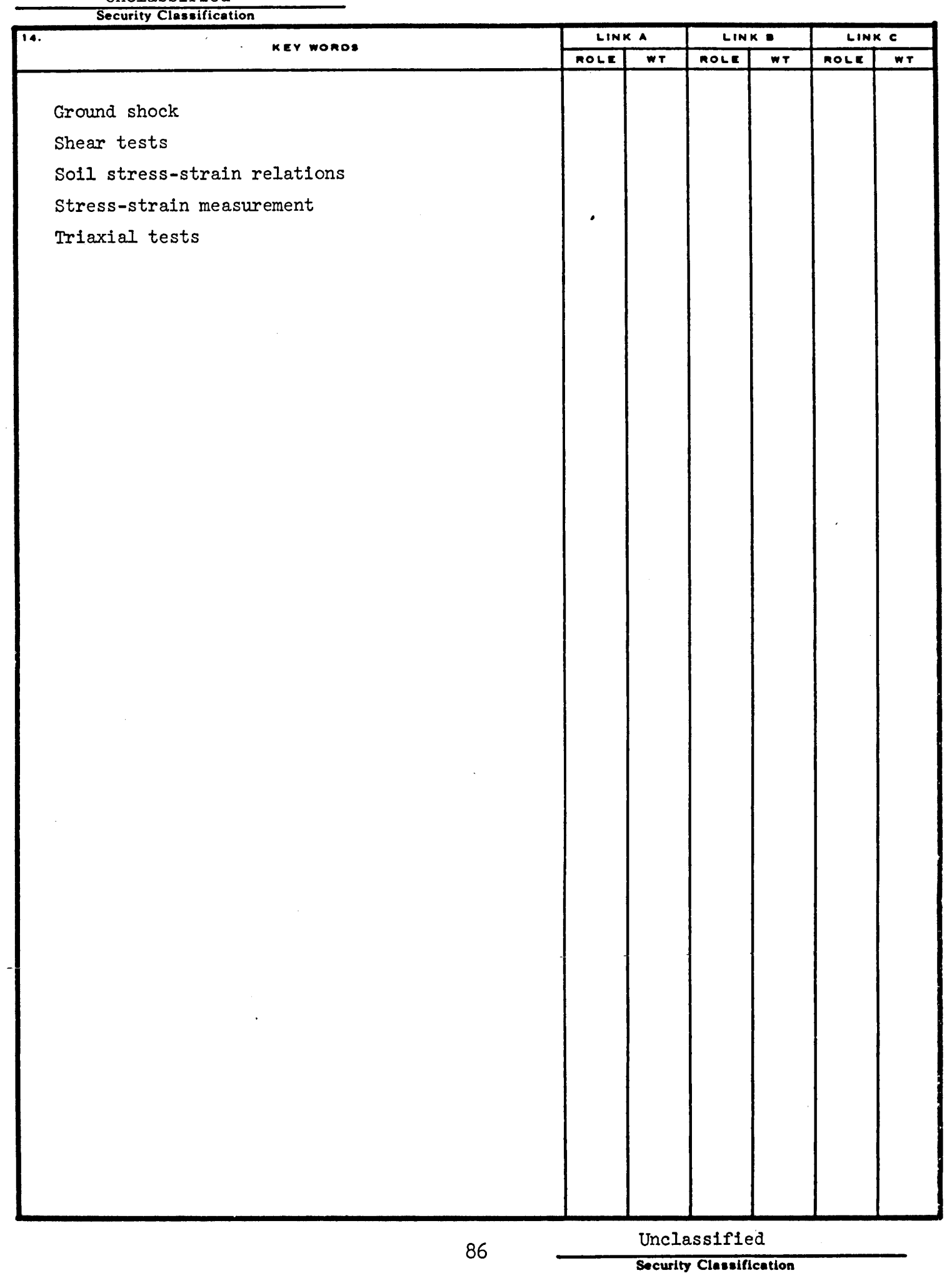

